\title{
Review Article \\ Regulation of Breast Cancer and Bone Metastasis by MicroRNAs
}

\author{
S. Vimalraj, P. J. Miranda, B. Ramyakrishna, and N. Selvamurugan \\ Department of Biotechnology, School of Bioengineering, SRM University, Kattankulathur Tamil Nadu, 603 203, India
}

Correspondence should be addressed to N. Selvamurugan; selvamn2@yahoo.com

Received 17 June 2013; Revised 17 August 2013; Accepted 27 August 2013

Academic Editor: Benoit Dugue

Copyright (C) 2013 S. Vimalraj et al. This is an open access article distributed under the Creative Commons Attribution License, which permits unrestricted use, distribution, and reproduction in any medium, provided the original work is properly cited.

\begin{abstract}
Breast cancer progression including bone metastasis is a complex process involving numerous changes in gene expression and function. MicroRNAs (miRNAs) are small endogenous noncoding RNAs that regulate gene expression by targeting protein-coding mRNAs posttranscriptionally, often affecting a number of gene targets simultaneously. Alteration in expression of miRNAs is common in human breast cancer, possessing with either oncogenic or tumor suppressive activity. The expression and the functional role of several miRNAs (miR-206, miR-31, miR-27a/b, miR-21, miR-92a, miR-205, miR-125a/b, miR-10b, miR-155, miR-146a/b, miR335, miR-204, miR-211, miR-7, miR-22, miR-126, and miR-17) in breast cancer has been identified. In this review we summarize the experimentally validated targets of up- and downregulated miRNAs and their regulation in breast cancer and bone metastasis for diagnostic and therapeutic purposes.
\end{abstract}

\section{Introduction}

Breast cancer is a malignant breast neoplasm originating from breast tissues, and its advanced form tends to metastasize into bone. It comprises $10.4 \%$ of all cancer incidences among women, and it is the most common type of nonskin cancer in women. Breast cancer is about 100 times more common in women than in men although males tend to have poorer outcomes due to delays in diagnosis [1-3]. Breast cancer metastasizes into bone is the process of spreading of the advanced form of breast tumor cells into bone. Thus the interactions between breast tumor cells and bone cells lead to impede the bone remodeling, in specific breast tumor which is recorded to predominantly increase the osteoclastic activity [4]. The radiation and chemotherapy are the potential and effective for cancer treatment, but they lead to side effects by destroying noncancerous cells or healthy cells, and this type of heavy toxic burden impedes the immune system; hence the patient would be susceptible to other infections. In addition, the continuous treatment of radiation and chemotherapy results in less effective destroying cancer cells because of resistance gained $[5,6]$. There is an urge to bring out novel technique(s) for facilitating the diagnostic and therapeutic approaches for cancer treatment.
1.1. Molecular Diagnostics and Therapies for Breast Cancer. The traditional clinical approach to treat breast cancer involves a combination of existing surgical-, chemical-, and radiation-based therapies. Surgical options include lumpectomy, quadrantectomy, mastectomy, and modified radical mastectomy. These procedures are sometimes followed by adjuvant therapy depending on the body conditions of patients [7]. Hormonal therapies include selective estrogen receptor modulators (SERMs), such as tamoxifen, and aromatase inhibitors, such as anastrozole. Chemotherapy includes traditional chemotherapies as well as specific drugs such as trastuzumab, a monoclonal antibody to the HER2/ neu receptor. There may be possibility of toxicities or unwanted side effects associated with their administration that negatively affect the patient $[8,9]$.

Molecular diagnostic tests deal with personalized diagnostic information and allow specific treatment plans confining resistance, non response, and toxicity. The analysis of miRNAs may identify their role in decision making process for diagnostic and therapeutic approaches. Several RNAbased molecular diagnostic tools such as microarrays or quantitative reverse transcription (qRT)-PCR analysis focus on gene expression $[9,10]$. Recently several studies indicate the significant differential expression and functional role of 


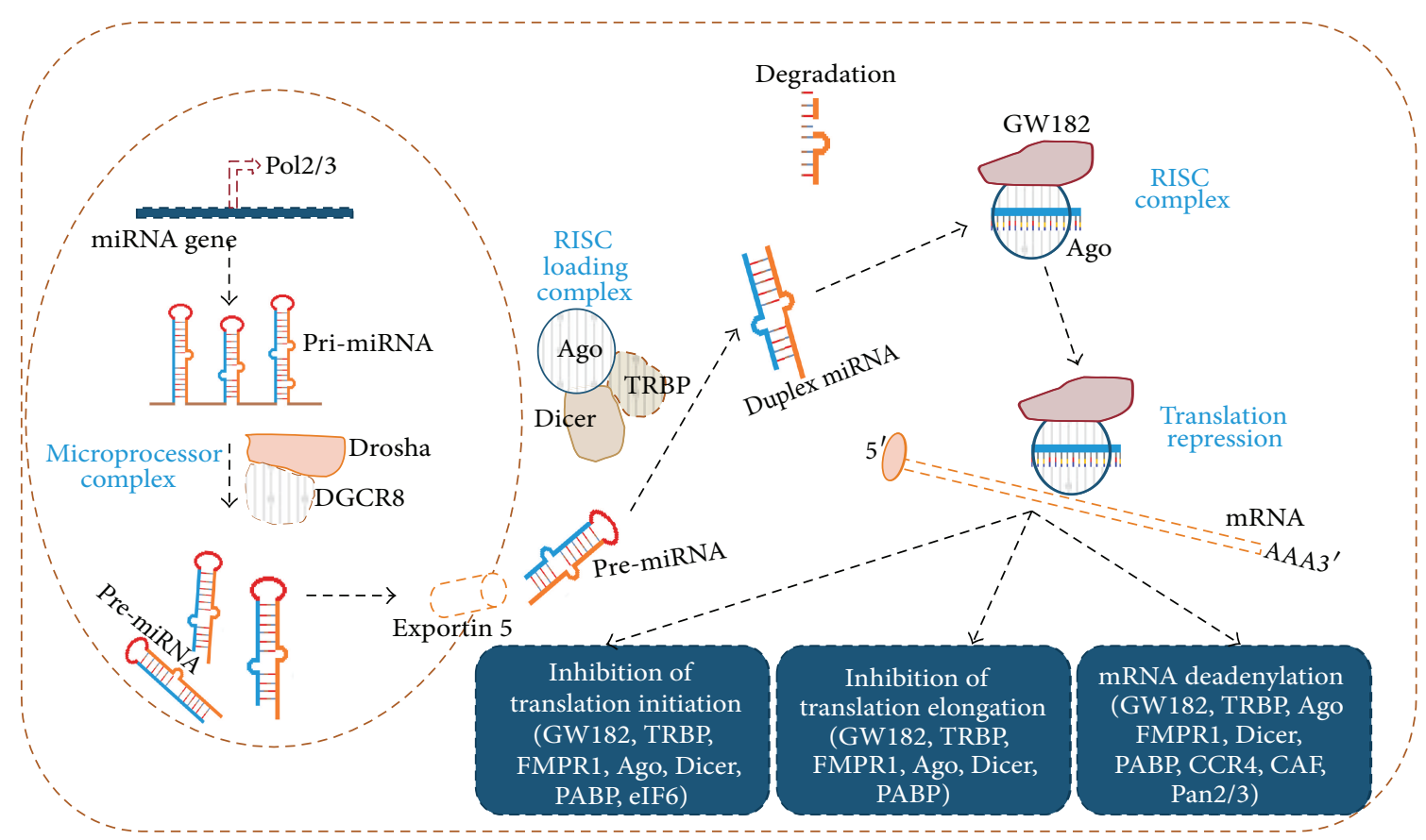

FIGURE 1: Biogenesis and function of microRNAs. RNA polymerase $2 / 3$ binds to the promoter region of specific DNA sequence and forms a hair pin structure of the pri-miRNA. DGCR8 (Pasha) associates with protein Drosha which process pri-miRNA to pre-miRNA (by cleaving nucleotides from hair pin). Pre-miRNA is exported into cytoplasm with shuttle protein exportin. In mammals, the pre-miRNA is loaded onto a multiprotein complex consisting minimally of Dicer, Tar RNA Binding Protein (TRBP), and Ago2. The RNase III enzyme Dicer processes the precursor by cleaving the stem loop to produce the mature miRNA (canonical pathway) [11-13]. The precursor can be loaded directly onto Ago 2 protein, and this Argonaute cleaves the precursor RNA of this miRNA [13]. The $5^{\prime}$ nucleotide of the miRNA guide strand, especially $5^{\prime}$ $\mathrm{U}$, functions as an additive anchor and helps Ago proteins to load mismatch-containing miRNA/miRNA duplexes [14]. Of the two strands the guide strand is integrated with RISC forming miRNA-RISC complex, and other strand is degraded [13-16]. RISC is involved in inhibition of translation initiation, inhibition of translation elongation, or mRNA deadenylation [15-17].

miRNAs in breast cancer, bone metastases, and other cancers, suggesting that miRNAs could be a valuable biomarker for cancers. However, the regulatory mechanisms of miRNAs in breast cancer and bone metastasis remain unclear. Here we have systematically summarized the experimentally validated targets of up- and downregulated miRNAs along with their regulation in breast cancer and bone metastasis for diagnostic and therapeutic purposes.

1.2. MicroRNAs Synthesis. MicroRNAs (miRNAs) are a class of tiny noncoding endogenous RNA molecules, only 18-25 nucleotides long. These small molecules have been shown to play critical regulatory roles in a wide range of biological and pathological processes. miRNAs may regulate cellular gene expression at the posttranscriptional level by suppressing translation of protein coding genes or cleaving target mRNAs to induce their degradation through imperfect pairing with target mRNAs of protein coding genes at $3^{\prime}$ UTR (untranslated region). The interacting region of $5^{\prime}$ end of miRNA nucleotides ( 2 to $8 \mathrm{nt}$ ) is called seed sequence [1820]. However, few reports emphasized that miRNAs can also target at $5^{\prime}$ UTRs and protein coding regions of mRNA [18, 19, 21, 22]. According to miRBase, 2578 mature and 1872 precursor forms of miRNAs have been identified in human (http://www.mirbase.org/). MicroRNAs are transcribed with
RNA polymerase II (Figure 1). The RNA polymerase binds to the promoter region of specific DNA sequence and forms a hair pin structure of the pri-miRNA. The transcript thus obtained is methylated at $5^{\prime}$ region and polyadenylated at $3^{\prime}$ region which undergoes posttranscriptional splicing resulting in pri-miRNA. If the stem loop is found in $3^{\prime} \mathrm{UTR}$, the transcript serves as pri-miRNA $[11,18]$. The pri-miRNA (poly or monocystronic) has about $1 \mathrm{~kb}$ nucleotides in length, and its double stranded region of hair pin structure is recognized by nuclear protein DiGeorge syndrome critical region 8 (DGCR8 or "Pasha" in invertebrates) [11, 12]. DGCR8 associates with protein Drosha which process pri-miRNA to pre-miRNA (by cleaving nucleotides from hair pin). PremiRNAs $(\sim 70 \mathrm{nt})$ have $3^{\prime}$ overhang due to cleavage by RNA pol II. Pre-miRNA is exported into cytoplasm with shuttle protein exportin. This is an energy coupled transport with GTP bound Ran protein, a nuclear transport receptor [13].

In cytoplasm the Dicer, an RNase III enzyme, cleaves premiRNA to give double stranded miRNA duplex [14]. In mammals, the pre-miRNA is loaded onto a multiprotein complex consisting minimally of Dicer, Tar RNA Binding Protein (TRBP), and Ago2. The Dicer processes the precursor by cleaving the stem loop to produce the mature miRNA. Ago2 binds with mature miRNA to form the RISC (RNA induced silencing complex) complex to target specific mRNA. This is canonical miRNA biogenesis (Figure 1). miRNA biogenesis 


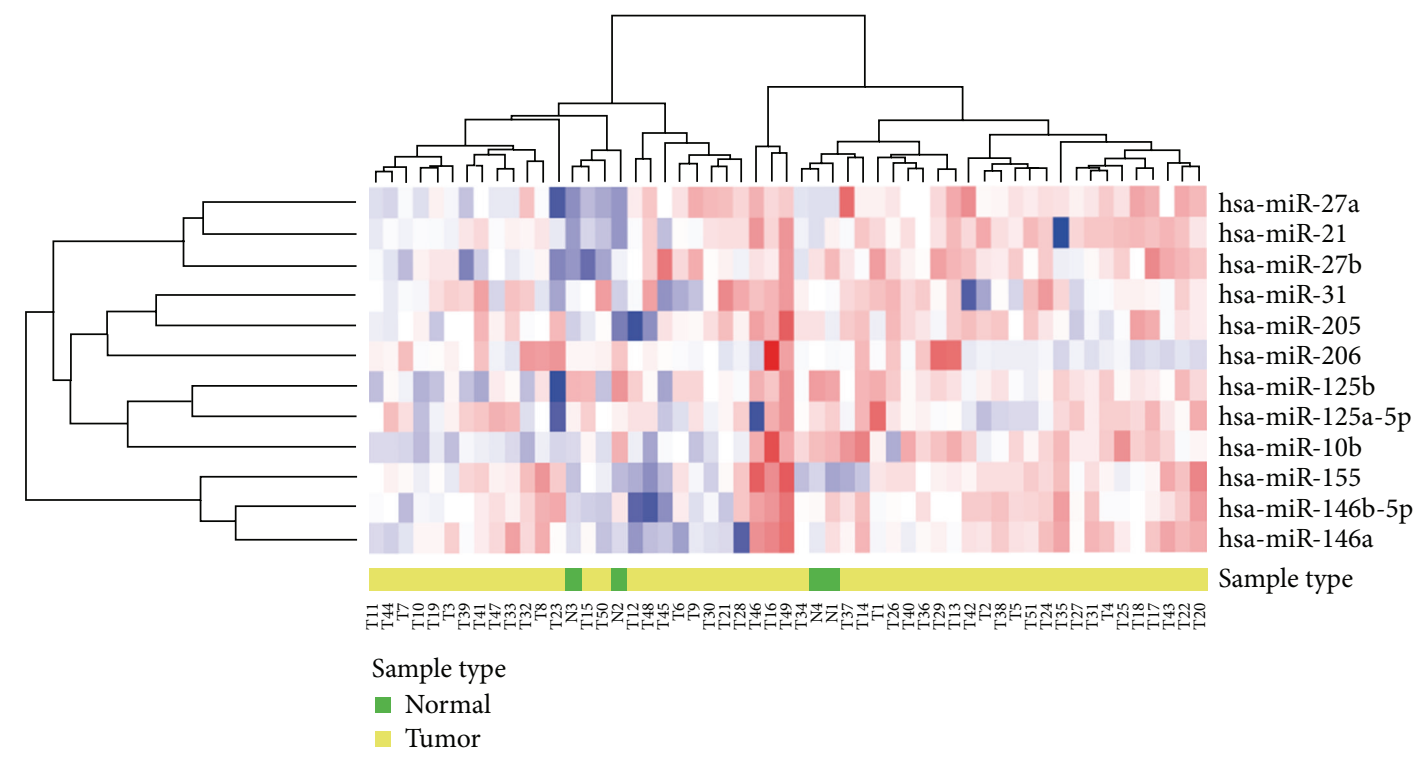

FIGURE 2: Heat map of differential expression of miRNAs in human normal and tumor breast cells. Differential expression of miR-206, miR31, miR-27a, miR-21, miR-27b, miR-205, miR-125b, miR-125a-5p, miR-10b, miR-155, miR-146b-5p, and miR-146a was identified in normal breast and breast tumor cells by miRNA body map along with the hierarchical cluster analysis. Expression of miRNAs is represented as blue (downregulated), red (upregulated), and white colors (no significant change or absence of data). Here, T represents breast tumor cells and $\mathrm{N}$ represents breast normal cells.

can also depend on Ago2 protein, instead of Dicer. In case of miR-451, the precursor is loaded directly onto Ago2, and this protein cleaves the pre-miRNA. The mature miR-451 is bound by Ago 2 to form the RISC (RNA induced silencing complex) that targets erythropoietic-specific mRNAs [15]. The $5^{\prime}$ phosphate of the miRNA strand is essential for duplex loading into Ago, and the preferred $5^{\prime}$ nucleotide (uridine) of the miRNA strand (guide strand) and the base pairing status in the seed region and the middle of the $3^{\prime}$ region function as additive anchors to Ago [16]. Of the two strands the guide strand is integrated with RISC and other strand; that is, passenger stand is degraded due to its instability $[16,17]$. The miRNA/RISC complex attaches to the messenger RNA (mRNA) in one of the two ways. (1) When the sequences are perfectly complementary, the miRNA/RISC complex binds tightly to the mRNA and, via the enzyme Ago2, the mRNA is degraded [23]. The poly A binding protein (PABP-) dependent poly(A) nuclease 2 (Pan2-) Pan3 deadenylases are involved in mRNA deadenylation that could lead to mRNA degradation $[16,18,23]$. Poly A seems to give stability to the mRNA. (2) More commonly, when the sequences are imperfectly complementary, the miRNA/RISC complex binds and inhibits translation of the mRNA without degradation. The final outcome of either of these pathways is a decrease in the protein level of the target gene. The question of whether a miRNA induces translation inhibition or mRNA degradation would depend on the level of individual miRNA, specific targets, and cell backgrounds $[18,19]$ (Figure 1).

\section{2. miRNAs Expression}

MicroRNAs play an important role in normal functioning of the cells. Deregulation of miRNAs has been associated with several disease conditions [19]. Most of the miRNAs are either upregulated or downregulated, thereby acting as oncogenes or tumor suppressor genes by regulating their target genes. To evaluate the differential expression of preferred miRNAs between normal and breast cancer cells we performed miRNA body map analysis (http://www.mirnabodymap.org/) based on database instructions [24]. This database holds expression of miRNAs from normal and diseased tissues by RT-qPCR analysis, and the data allows the analysis of differential expression of miRNAs between specific tissues or samples. The heat map provided here emphasizes the differential expression of miR-206, miR-31, miR-27a, miR-21, miR-27b, miR-205, miR-125b, miR-125a-5p, miR-10b, miR155, miR-146b-5p, and miR-146a in 51 breast cancer samples and 4 normal breast samples of human (Figure 2). The heat map based on color (blue: down regulation and red: up regulation) and cluster clearly depicts the differential expression of preferred miRNAs between normal and tumor breast cells. The up- or downregulated miRNAs are correlated with the expression of their targeted genes, which could provide valuable physiological and pathological information about their systems [18-20].

\subsection{Oncogenic miRNAs}

2.1.1. miR-21. In breast cancer, miR-21 was found to be overexpressed [10,25]. The proteomic analysis revealed that TPM1 (Tropomysin) expression is reduced in tumor cells and it is a target gene of miR-21 [25]. TPM1 is a tumor suppressor gene which regulates microfilament organization and anchorage-independent growth [26]. It was found that there is a putative miR-21 binding site at the $3^{\prime}$ UTR of TPM1 variants. When TPM1 was overexpressed in breast cancer 
(MCF-7) cells, the anchorage-independent growth was suppressed [25]. A tumor suppressor gene, phosphatase and tensin homolog (PTEN), is also targeted by miR-21 [27]. Upregulation of miR-21 limits the activity of PTEN, and PTEN is known to limit the activity of PI3K pathway [28]. Another tumor suppressor gene product, PDCD4 (programmed cell death), was originally characterized as an inhibitor of cellular transformation in a mouse cell culture model [29]. Studies have shown that the levels of PDCD4 mRNA as well as protein were upregulated by miR-21 inhibition indicating that PDCD4 is an important functional target for miR-21 $[30,31]$. In all-transretinoic acid (ATRA) treatment, miR21 was selectively induced in ER- $\alpha$ positive cells and not in ER- $\alpha$ negative cells. Based on differential expression of genes regulated by ATRA in ER- $\alpha$ positive and ER- $\alpha$ negative cells, three more direct miR-21 targets (proinflammatory cytokine (IL1B), adhesion molecule (ICAM-1 and PLAT), tissue-type plasminogen activator (tPA)) have been predicted [32]. miR21 downregulated MSH2 and SMAD7 in TGF- $\beta$ pathway and caused breast cancer progression and upregulated human epidermal growth factor receptor 2, and thus it acted as oncogene $[33,34]$. miR-21 with numerous gene targets in breast cancer progression is positively regulated by a protein, named nucleolin (NCL), a major nucleolar protein, at posttranscriptional level. Overall it is emphasized that miR-21 is one of the important miRNAs involved in the regulation of cancer cells $[35,36]$.

2.1.2. miR-10b. In metastatic breast cancer cell lines, miR$10 \mathrm{~b}$ was upregulated after activation of twist transcription factor, and its overexpression increased with tumor size and invasiveness. It appeared that miR-10b inhibits translation of homeobox D10 (HOXD10) resulting in induction of the prometastatic gene product, RHOC [37]. This RHOC in turn favors cell migration and invasion. The initiation of metastasis in nonmetastatic cancer with overexpression of miR-10b in an in vivo experiment proved its role in the metastasis of breast cancer. Interestingly it was identified that miR-10b was down-regulated in breast cancer cells compared to normal breast cells providing evidence that miR-10b does not play any role during initial tumor development [38] and proliferation [39]. In contrast to its oncogenic role, it was also identified that miR-10b targeted various oncogenic genes such as FLT1, BDNF, and SHCl, a signal transduction factor [10]. The targets of miR-10b identified are BUB1, PLK1, and CCNA2 [40]. miR-10b also targets syndecan-1 and promotes breast cancer metastasis and invasiveness [41].

2.1.3. $m i R-125$. Data reported that miR- 125 is likely to down regulate genes which promote tumorigenesis. Overexpression of miR-125a or mir-125b in an erb2-dependent cancer cell line (skbr3) suppressed her2 and her3 transcript and protein levels, which decreased cell motility and invasiveness [42]. miR-125a and miR-125b were significantly downregulated in her2-positive breast cancers. Computation analysis confirmed target sites at the $3^{\prime}$ UTR regions of her2 and her 3 for these miRNAs [43]. The role of miR-125 as an oncogene has been validated by its role in suppressing various tumor suppressor genes including p53 gene [44].

2.1.4. $\mathrm{miR}-155$. miR-155 has been shown as over-expressed in breast cancer, and further it is upregulated in normal mouse mammary gland epithelial cells (NMuMG cells) by the TGF$\beta /$ Smad4 pathway, and it mediates TGF- $\beta$-induced EMT and cell invasion $[10,45,46]$. The ectopic expression of miR-155 in NMuMG cells disrupted proper tight junction formation and promoted cell migration and invasion. Conversely, antagonizing miR-155 in NMuMG cells reduced the occurrence of TGF- $\beta$-induced EMT and cell migration and invasion. miR-155 directly inhibits the expression of RhoA, a gene that regulates many cellular processes including cell adhesion, motility, and polarity and is an important modulator of cell junction formation and stability. It is speculated that TGF- $\beta /$ Smad4 regulates expression of miR-155 resulting in down regulation of RhoA protein expression to drive EMT progression. In another study, it was shown that miR-155 is associated with cancer invasiveness in human primary breast carcinoma; that is, miR-155 is highly expressed in invasive tumors but not in noninvasive cancer tissues $[45,46]$.

Ectopic expression of miR-155 induces cell survival but its knockdown leads cell to apoptosis and enhances chemosensitivity. FOXO3a has been identified as direct target for miR-155. Inverse correlation of FOXO3a and miR-155 has been observed in breast cancer cell lines and tumors. miR155 directly interacts with $3^{\prime}$ UTR of FOXO3a and blocks its translation. Hence, FOXO3a is negatively regulated by miR-155, and FOXO3a mediates miR-155 function in the control of breast cancer cell survival and growth [47]. Further, the phenomenon of up regulation of hexokinase 2 (hk2), which enhances the metabolic activity of breast cancer cells by miR-155, makes it as a potential candidate for anticancer therapy. miR-155 first activates signal transducer and activator of transcription 3 (STAT3), a transcriptional activator for hk2, and secondly target $\mathrm{C} / \mathrm{EBP} \beta$ [48]. It has been shown that tumor-associated circulating miRs (miR10b, miR-34a, miR-141, and miR-155) are elevated in the blood of breast cancer patients, and hence there would be feasibility and clinical utility of circulating miRNAs as biomarkers for the detection and staging of breast cancer [49]. It was evident that miR-155 inhibited BMP2-, BMP6-, and BMP7 and induced ID3 expression by targeting SMAD1, SMAD5, HIVEP2, CEBPB, RUNX2, and MYO10, components of the BMP signaling cascade [50]. Recent findings indicate that miR-155 contributes to cell proliferation by down regulation of TP53INP1 in estradiol promoted breast cancer cells [51]. miR-155 also downregulated tumor suppressor genes such as p53 [52], CDC73 [53], and VHL [54] in breast cancer cells. In Table 1, the detailed information about oncogenic miRNAs, their target genes, and their regulation during breast cancer progression is provided.

\subsection{Tumor Suppressor miRNAs}

2.2.1. $m i R-206$. A differential expression of miR-206 was observed in cancer and normal tissues. miR-206 targets 


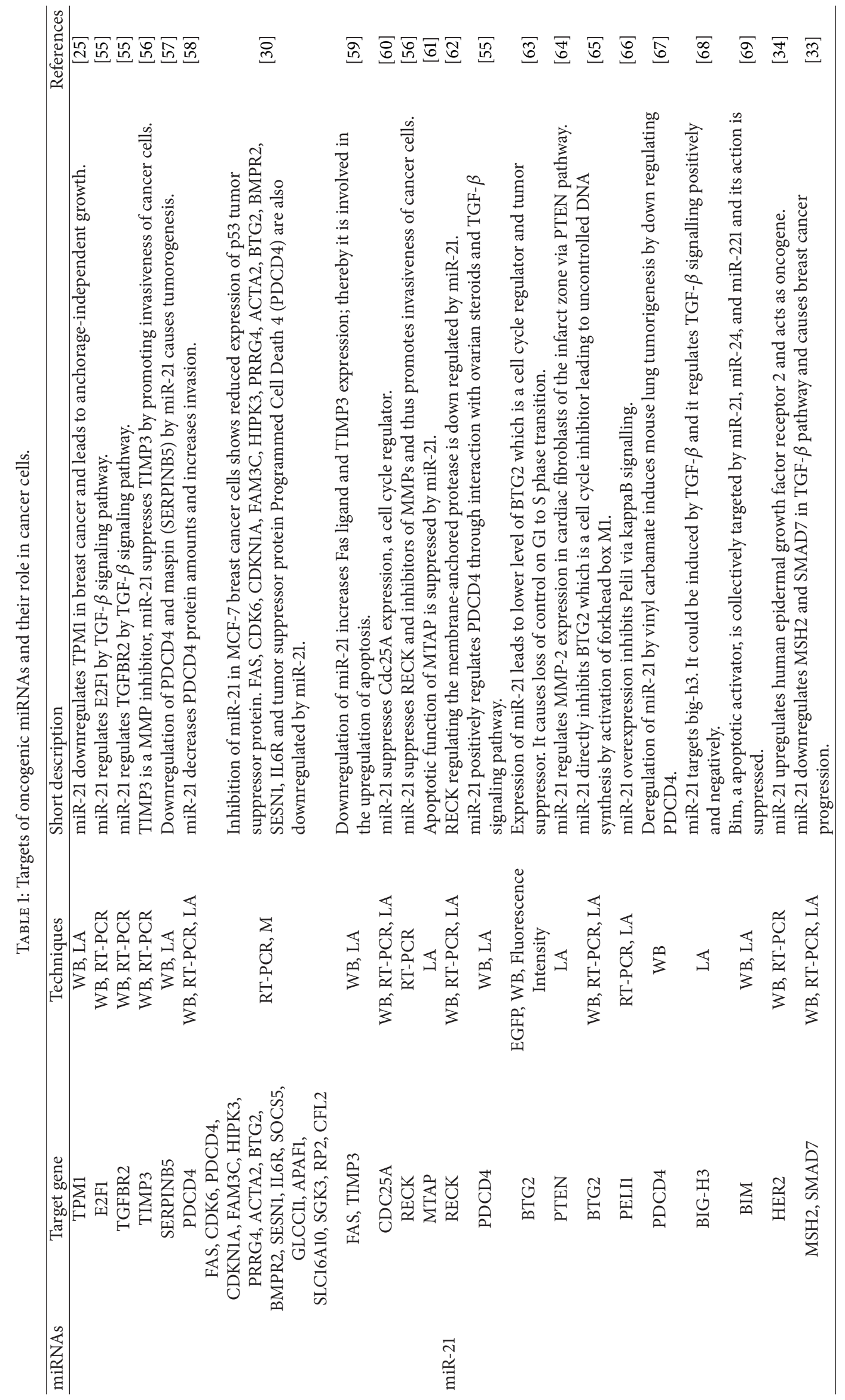




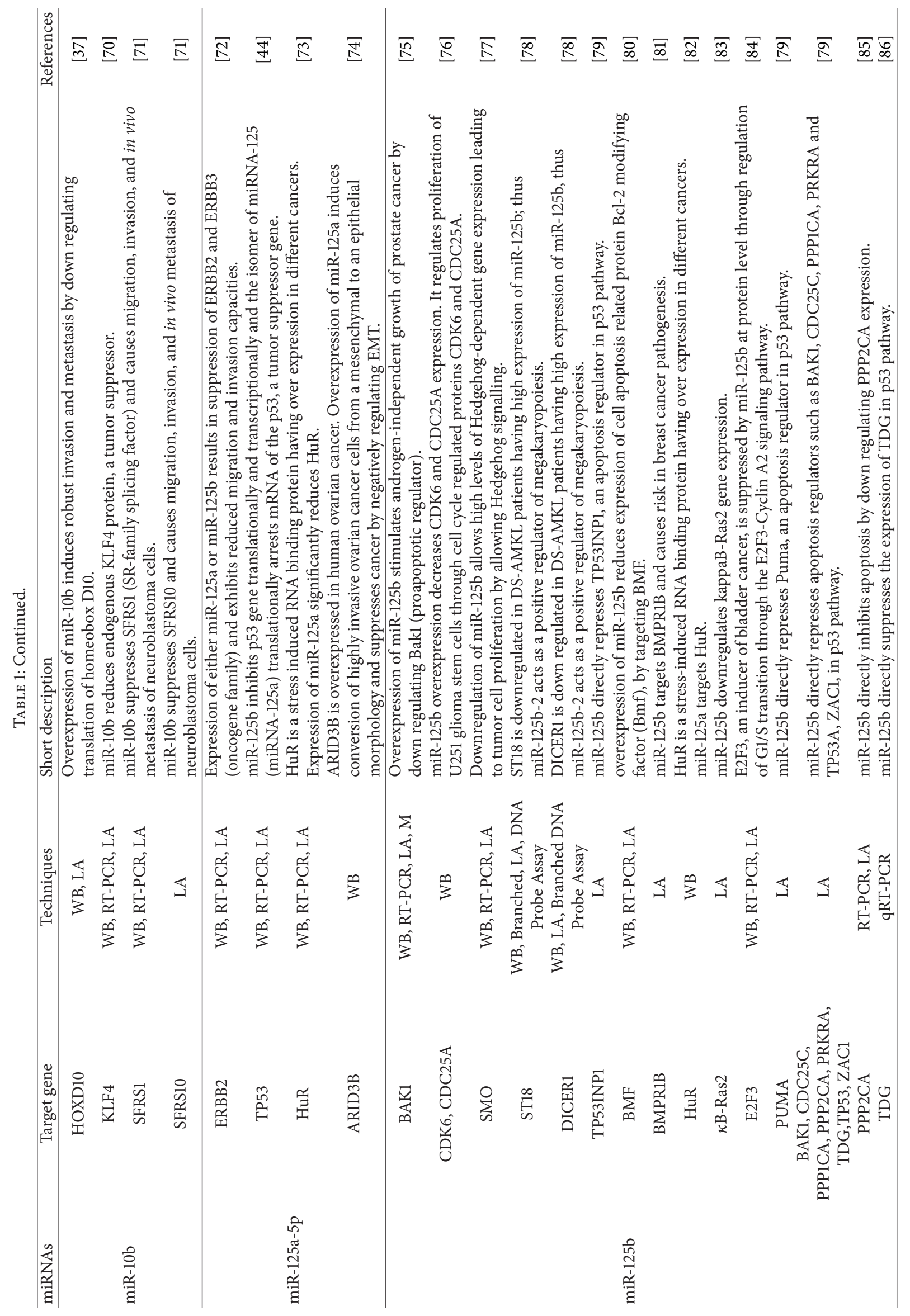




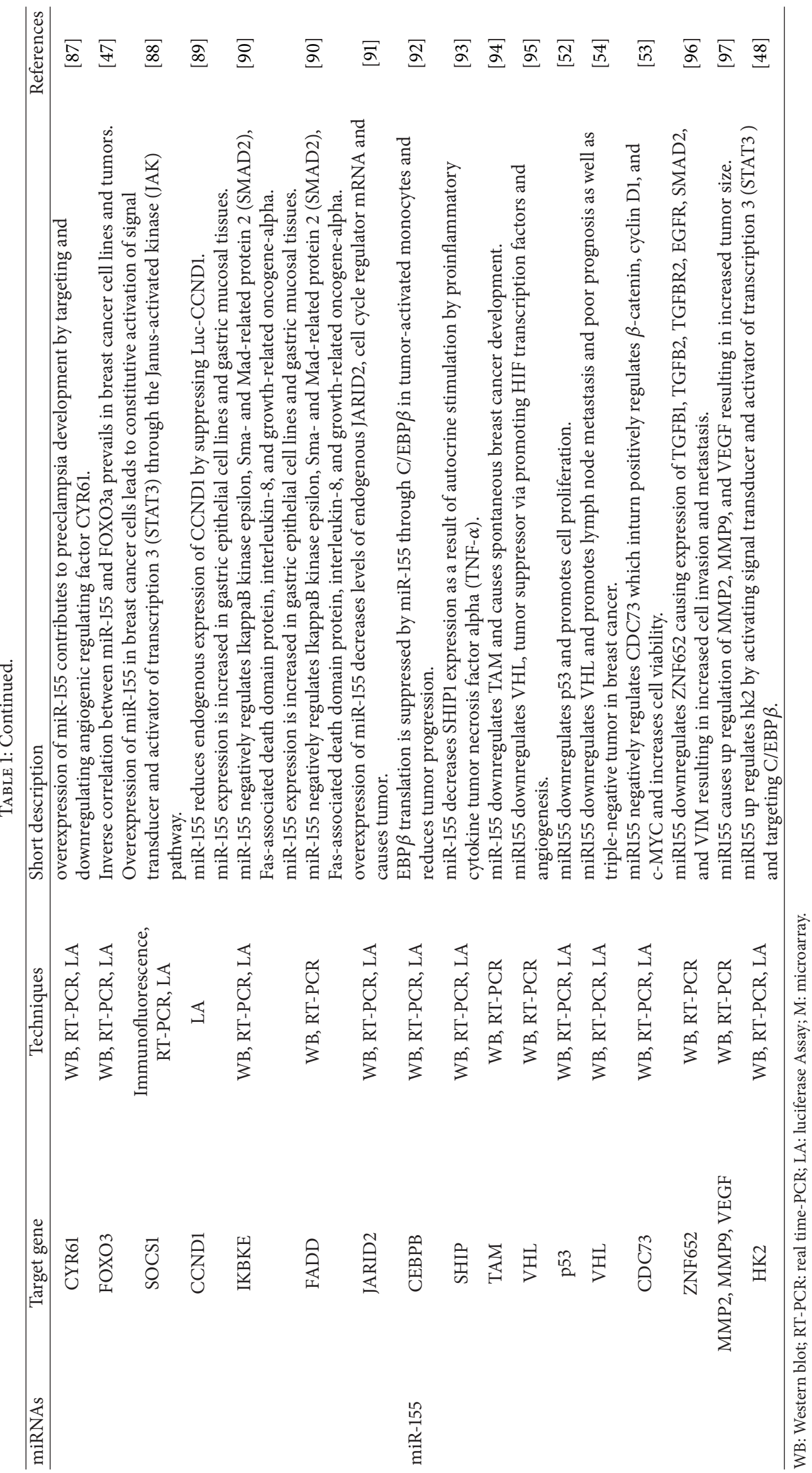


hormone related gene ER- $\alpha$ (estrogen receptor alpha) [98]. ER- $\alpha$ is important in estrogen related growth, and its expression level is marked in prognosis of ER- $\alpha$ positive breast cancer cells [99]. There are two miR-206 binding sites within the $3^{\prime}$-UTR of human ER- $\alpha$, and miR-206 downregulates ER- $\alpha$ mRNA and protein expression in breast cancer cells [99]. The expression levels of miR-206 have been shown to be much higher in ER- $\alpha$ negative than in ER- $\alpha$ positive breast cancer tumors and that the more ER- $\alpha$ positive cells present in the tumor, the less miR-206 expression seen, suggesting that miR-206 is a key factor for the regulation of ER- $\alpha$ expression in the development and progression of human breast cancer [99]. There was decreased miR-206 expression in ER- $\alpha$ positive human breast cancer tissues and that introduction of miR-206 into estrogen dependent breast cancer cells inhibited cell growth [98]. Thus, it appears that miR-206 could be a novel candidate for ER $\alpha$-specific endocrine therapy in breast cancer. Esterogen involves in breast cancer cell proliferation by activating ER $\alpha$ receptor. It is recorded that around $70 \%$ of breast cancers are ER positive. Inhibitors of ER $\alpha$ such as tamoxifen and aromatase are widely used for treatment of $\mathrm{ER} \alpha$ positive breast cancer patients, but, during the treatment, they are likely to prone for endocrine resistance [100]. Hence, there is a need for genetic level modifiers of ER $\alpha$ expression which could be achieved by miRNAs. In the mammary epithelium, it was seen that miR206 down regulates Tachykinin1 and GATA3 genes, which are known as breast cancer markers [101]. The down regulation of miR-206 could lead to cancer progression by up regulating expression of cyclin D2 [102].

2.2.2. $m i R-31$. miR-31 prevents metastasis at multiple steps by inhibiting the expression of prometastatic genes. Introduction of miR-31 in metastatic breast cancer cells suppressed metastasis-related functions like motility, invasion, and resistance to anoikis in vitro and metastasis in vivo [103]. The ability of miR-31 to inhibit metastasis was attributable to inhibiting expression of RhoA. The miR-31-mediated repression of RhoA affected both local invasion and early postintravasation events. It was suggested that the full spectrum of miR-31's effects on metastasis is elicited via the coordinate repression of multiple targets [103]. The expression of SATB2 gene is associated with increased tumor cell migration and invasion, and miR-31 acts as a tumor suppressor by directly binding to the $3^{\prime}$ UTR of SATB2 mRNA [104]. miR-31 also directly regulates FOXP3 by binding to the $3^{\prime} \mathrm{UTR}$ of FOXP3 mRNA. [105]. miR-31-P directly represses Dicer in MCF-7 breast cancer cells [106]. It has recently shown that miR-31 expression inhibits the oncogenic NF- $\kappa$ B pathway, and thus it acts as a tumor suppressor miRNA [107].

2.2.3. $m i R-146$. Breast cancer metastasis suppressor 1 (BRMS1) regulates expression of multiple genes linked to metastasis, including osteopontin (OPN), urokinase-type plasminogen activator (uPA), epidermal growth factor receptor (EGFR), fascin, and connexins [108]. miR-146 is more abundantly expressed in BRMS1-expressing cells. miR-146a and miR-146b are distinct genes encoded on chromosomes $5 q 33$ and 10q24, respectively. The mature products have similar targets because they differ only by two nucleotides near the $3^{\prime}$ end [108]. miR-146a negatively regulates IFN pathway by targeting the IFN regulatory factor 5 and STAT1 [109]. miR146a and miR-146b have been shown to inhibit both migration and invasion, suggesting that they play a role in metastasis [110]. Since miR-146a and miR-146b both reduce epidermal growth factor receptor (EGFR) expression and suppress metastasis [110], it is suggested that these miRNAs could have a therapeutic potential to suppress breast cancer metastasis.

2.2.4. $m i R-91$. miR-91 is also known as miR-17-5p, located on chromosome 13q31, a genomic region that undergoes loss of heterozygosity in breast cancer [111]. The oncogene amplified in breast cancer (AIB1) is a direct target of miR17-5p. The protein encoded by the AIB1 gene is a steroid receptor coactivator that enhances the transcriptional activity of ER $\alpha$ and E2F1. miR-17-5p represses the translation of AIB1 mRNA, thereby inhibiting the function of E2F1 and ER $\alpha$ genes. Down regulation of AIB1 by miR-17-5p results in suppression of estrogen stimulated proliferation and estrogen/ER independent breast cancer cell proliferation [112]. In breast cancer cells, cyclin D1 (CCND1), which is over expressed in cancers, was identified as a direct target of miR-17-5p. It was shown that miR-17-5p inhibits the proliferation of breast cancer cells by suppressing cyclin D1 protein [113]. There is higher expression of miR-17-5p in the noninvasive breast cancer cell lines (BT474, MCF7, MDA-MB-468, and T-47D) compared with highly invasive lines (MDA-MB-231, Hs578T, and SKBR3) [114]. The detailed information about tumor suppressor miRNAs, their target genes, and their regulation in breast cancer is listed in Table 2 .

\subsection{Oncogenic/Tumor Suppressor miRNAs}

2.3.1. $m i R-205$. The miRNA profiling data indicated that breast cancers without vascular invasion had high level expression of miR-205 compared to breast cancers with vascular invasion. miR-205 was downregulated in breast tumor tissues as well as breast cancer cell lines; in contrast, miR-205 was highly expressed in normal breast tissues and in the nonmalignant breast epithelial cell line MCF-10A [72, 125]. Cell proliferation was inhibited in MCF-7 cells when they were transfected and over-expressed with miR-205 vector. Over-expression of miR-205 allowed cells to grow on soft agar very slowly indicating the reduced anchorage-independent growth. The in vivo metastasis assays showed that miR-205 suppressed invasiveness in human breast cancer cells (MDA-MB-231) [72]. miR-205 targets and affects expression of ErbB3 and VEGFA genes which are involved in tumorogenecity $[72,125]$. ErbB3 is a member of ErbB tyrosine kinase receptor family, which is frequently overexpressed in breast cancer. There are correlations between ErbB3 expression levels and tumorigenesis in breast cancer [126, 127]. VEGF-A is a key regulator of angiogenesis, and it plays a key role particularly in tumor metastasis. miR-205 directly targets 


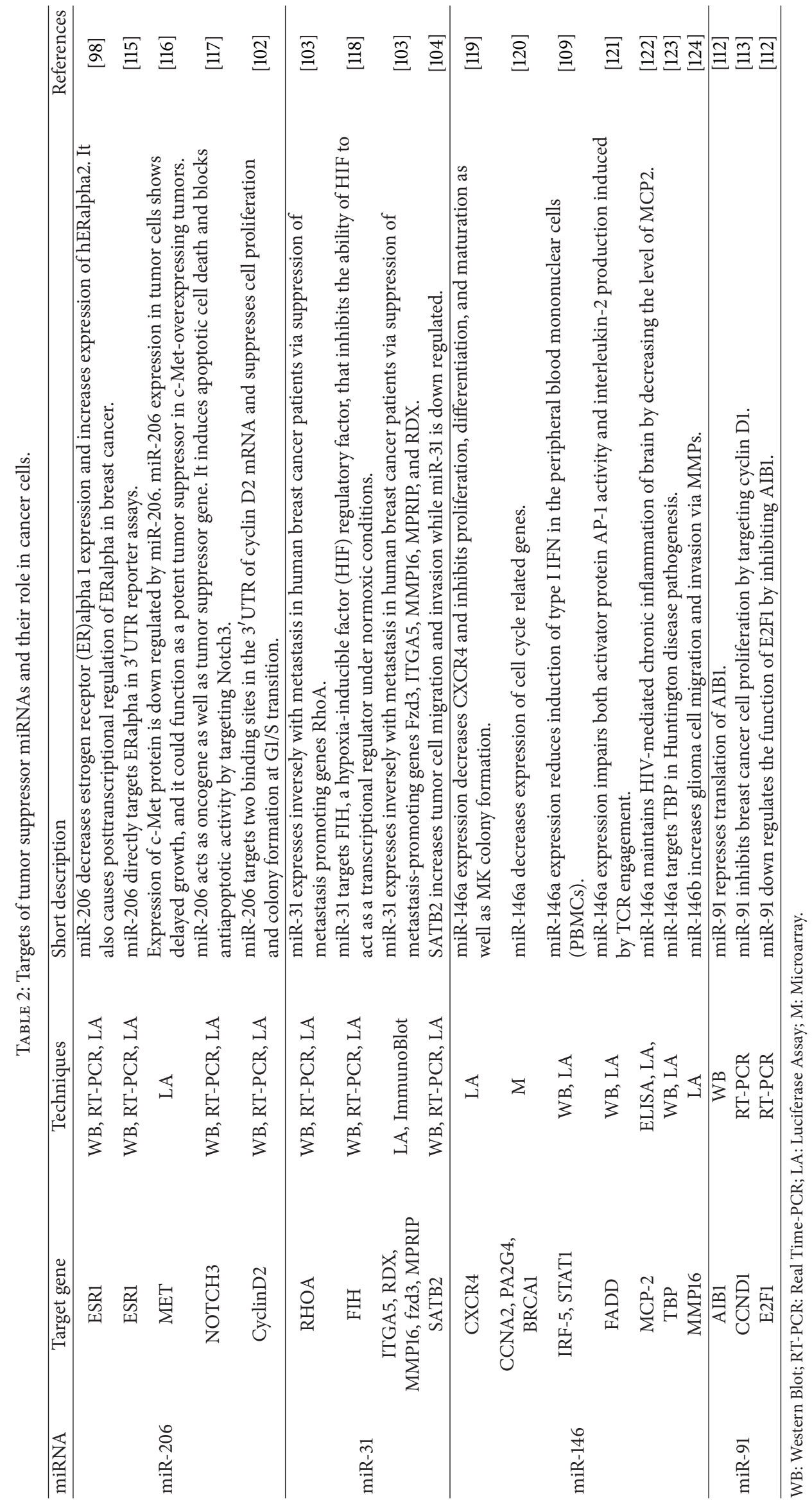


VEGF-A by interacting with the putative miR-205 binding site in its $3^{\prime}$-UTR. Therefore, miR-205 can negatively regulate the expression of ErbB3 and VEGF-A [72], and the results suggested that miR-205 may function as a tumor suppressor in breast cancer. miR-205 can act as either tumor suppressor or oncogene and that is context-dependent [127]. The expression profile and the function of miRNAs vary in different breast cancer phenotypes (positive and negative ErbB2). In addition, the patients' history such as age, tumor virulence, stage of tumor, node status, tumor proliferation index, and other physical and chemical parameters may influence the activity of miRNAs [43, 72, 128-130].

2.3.2. $m i R-27$. miR-27a was upregulated in breast cancer, and it appears to target the transcriptional cofactor, zinc finger and BTB domain containing 10 (ZBTB10) [131]. ZBTB10 represses the specificity protein 1 (SP1) transcription factor. The SP1 transcription factor is over expressed in many cancers and plays a role in the G0-G1 to $S$ phase progression in breast cancer cells [132]. So it implies if expression of ZBTB10 is reduced, miR-27a indirectly up regulates SP1 thus increasing $S$ phase progression and functions as an oncogene. miR27a can regulate E2-responsiveness in MCF-7 cells through suppression of ZBTB10, thereby enhancing expression of ER [131]. miR-27a also suppresses the cdc2/cyclin B inhibitor Myt-1 in MDA-MB-231 cells and thereby facilitates breast cancer cell proliferation. Thus, the oncogenic activity of miR27a in MDA-MB-231 cells is due to suppression of expression of ZBTB10 and Myt-1 proteins [132]. It was hypothesized that miR-27 indirectly regulates the SP family protein with the up regulation of the zinc finger ZBTB10 gene, a putative SP repressor [133]. miR-27b, a homologous to miR-27a, sharing 20 out of 21 nucleotides, is potentially associated with cytochrome p4501b1 (CYP1B1), which is known to catalyze the metabolism of certain procarcinogens and is over-expressed in a wide range of cancers $[134,135]$. In most patients, the expression level of miR-27b was found to be decreased in cancerous tissues, accompanied by a high level of CYP1B1 protein. A significant inverse association was observed between the expression levels of miR-27b and CYP1B1 protein. Thus, the decreased expression of miR-27b would be one of the causes of high expression of CYP1B1 protein in cancerous tissues, thus assuming the role for miR$27 \mathrm{~b}$ as a tumor suppressor gene [135]. Moreover, it is evident that the HER2/neu (ERBB2), EGF, and TNFA promote miR-23 and miR-27b expression (a prooncogenic factor) through the AKT/NF- $\kappa \mathrm{B}$ signaling cascade [136]. Thus, the expression and the function of miR-27 are likely to depend on the internal and external context of breast cancer and its phenotype. As we mentioned earlier, the patients' history such as age, tumor virulence, stage of tumor, node status, tumor proliferation index, and other physical and chemical parameters may influence the activity of miRNAs, that is, to act as either tumor suppressor or oncogene $[43,72,128-$ 130]. In Table 3, we provide more detailed information about miR-205 and miR-27, their target genes, and their regulation during breast cancer progression.

\section{Breast Cancer Bone Metastasis}

Bone metastases are common in patients with advanced breast cancer. Breast cancer cells preferentially select bone to metastasize since bone matrix is enriched with nutrients that support breast cancer cell growth. Once tumor cells embed within the bone environment, increased bone remodeling and bone destruction are common and are likely to mediate enhanced tumor growth in bone [137]. Metastatic cancer cells show a distinct biological profile from that of primary tumor cells by enhanced survival, motility, invasiveness, and resistance to chemotherapy [4]. Understanding the biological controls that signal tumor cell metastasis to bone and investigating the extent to which metastatic cancer cells differ from primary tumor cells with respect to miRNAs expression can provide valuable insight into growth of tumors in the bone microenvironment.

There are several lines of evidence indicating the involvement of specific miRNAs in suppressing or promoting breast cancer metastasis and in other cancers [138, 139]. miRNA signatures that regulate breast cancer metastasis can be observed either by tumor suppression or oncogenesis. They could either be downregulated (miR-30a/31/34a/125s/ $200 \mathrm{~s} / 203 / 205 / 206 / 342$ ) or upregulated (miR-10b/21/135a/155/ $221 / 222 / 224 / 373 / 520 \mathrm{c}$ ). In turn they influence the expression of various target genes positively or negatively. Nevertheless they are potentially considered to be therapeutic agents in tumor therapy [140]. Metastasis otherwise known as tumor migration is regulated by a number of miRNAs via direct or indirect pathways. The differential expression of miRNAs between metastatic cell lines was compared with the primary tumor, and there was a down regulation of expression of miR-22 in metastatic cancer cells [141, 142]. Expression of the tumor suppressor miRNAs such as let-7 and miR-22 was also consistently downregulated in metastatic cancer cells. These miRNAs' target genes were found to be oncogenes (ERBB3, CDC25C, and EVI-1T). Due to down regulation of miRNAs, there were higher levels of expression of these signaling proteins in metastatic cells [141]. Expression of tumor suppressor miRNAs such as let-7, miR-335, miR-126, and miR-206 were downregulated [143] resulting in increased metastatic potential via up regulation of genes involved in motility and proliferation. miR-335, miR-206, and miR-126 were selectively downregulated across a number of highly metastatic human cell lines compared to the general tumor cell population, and they had the ability to suppress metastasis of breast cancer cells to different organ sites. miR-335 suppresses metastasis and migration through targeting of the progenitor cell transcription factor SOX4 and extracellular matrix component tenascin C [143].

Up regulation of miRNAs' expression in metastases could also regress metastatic conditions. Valastyan et al. assessed the therapeutic potential of acutely expressing miR-31 in already-formed breast cancer metastases [142]. Activation of miR-31 in established metastases elicits metastatic regression and prolongs survival. In contrast, acute miR-31 expression fails to affect primary mammary tumor growth [142]. It is most likely that a distinct role is played by specific miRNA, and its expression of either down- or upregulation may not 


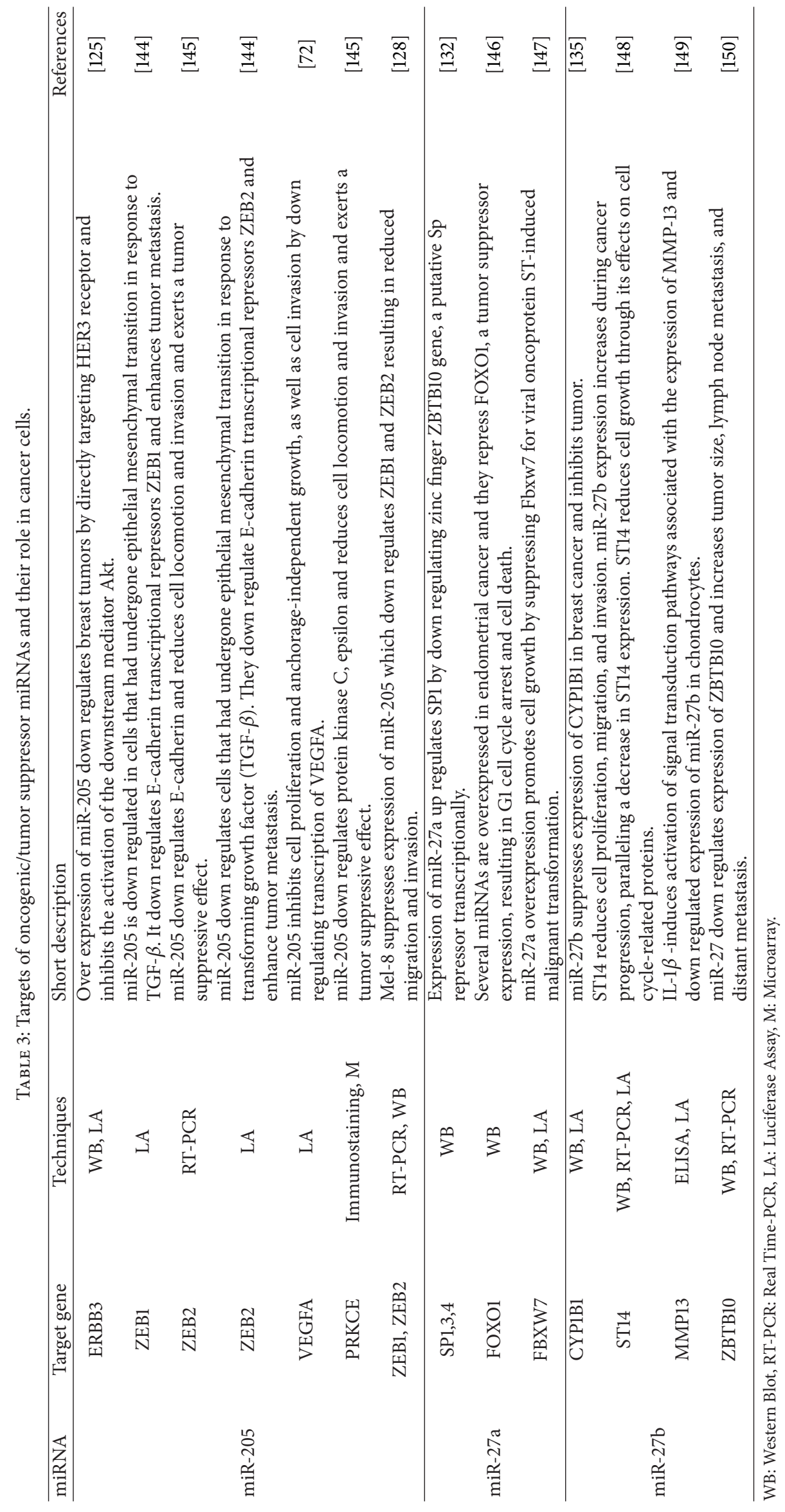


have impact on both primary tumor growth and metastatic conditions. Dicer is the key enzyme (ribonuclease) required for the biogenesis of miRNAs, and recent evidence indicates that Dicer may also be involved in tumorigenesis. The Dicer RNA variants $a$ and $b$ contain a very long $3^{\prime} U T R$, whereas $c$, d, and e variants contain very short $3^{\prime} \mathrm{UTR}$. Multiple let-7-binding sites were found in Dicer coding as well as $3^{\prime}$ UTR. Dicer mRNA expression is significantly correlated with the occurrence of distant metastases, even after adjusting for other prognostic parameters. In addition, Dicer mRNA expression has an independent prognostic value on metastatic disease in breast cancers [151]. The downregulation of Dicer expression by let-7 miRNA may be related to the metastatic spread of tumors [151]. The recent researches evolved with an understanding that there is a high probability of interaction of three different genes (c-myc, cyclin D1, and Runx2) in bone metastasis. Hence, studying the regulation of these genes by miRNAs would be a valuable approach for understanding of breast cancer progression to bone metastasis. Since a number of miRNAs target c-myc, cyclin D1, and Runx2 genes, in the following session, we are focusing on how these genes are regulated by miRNAs during bone metastasis.

3.1. $c-m y c$. The signaling pathways or components play fundamental role in regulating cell morphology, adhesion, and motility. Altering the signaling pathway could lead to tumorigenesis and metastasis, and miRNAs are found to be involved in this process. Rho-associated kinase (ROCK) is likely to enhance the metastatic propensity of breast cancer cells by stabilizing the actin cytoskeleton, enhancing actin-myosin contraction and promoting the c-myc pathway, including transcription of c-myc regulated miRNAs. Inhibition of ROCK-mediated signaling appears to be a promising and potentially specific approach to inhibit the breast cancer metastases. Further the expression of the cmyc regulated miR-17-92 cluster was elevated in metastatic breast cancer cells compared with nonmetastatic cells [152]. Furthermore, blockade of miR-17 decreased breast cancer cell invasion/migration in vitro and metastasis in vivo. Together, these findings suggest that augmented ROCK signaling contributes to breast cancer metastasis via indirectly up regulating miR-17 [152]. Raf kinase inhibitory protein (RKIP; also PEBP1), a member of the evolutionarily conserved phosphatidylethanolamine-binding protein family, has been implicated as a suppressor of metastatic progression. RKIP represses invasion, intravasation, and bone metastasis of breast tumor cells in part through a signaling cascade involving inhibition of MAPK, myc, and LIN28, leading to induction of let-7 and down regulation of its targets [153].

c-myc protein (oncoprotein) can induce tumors with a high frequency and can induce massive programmed cell death in most transgenic mouse model systems, with greater efficiency than other oncogenes [154]. It was substantiated with evidence that miR-142 is involved in overexpression of c-myc as it was translocated under the positive control of the promoter region of miR-142 during a casual chromosomal rearrangement. A mutation at the $3^{\prime}$-UTR of activation-induced cytidine deaminase (AID) mRNA, the binding site of miR-155, caused an increase in protein expression of c-myc resulting in high Myc-Igc translocation, a cause of cancer in Aicda mice [155]. It was noticed that miR-24 indirectly regulates c-myc via E2F2 thereby inhibiting cell proliferation [156]. It has been shown that myc activates expression of miR-9 which gives cancer a metastatic status [157]. The anaerobic metabolism of cancer cells (Warburg effect) is the major cause for creating an acidic environment to them, and the cancer cells' energy source (ATP) is generated via glutaminolysis. Mitochondrial glutaminase, an important enzyme in this process, is synthesized by transcriptional repression of miR-23a and $23 \mathrm{~b}$ by $\mathrm{c}-\mathrm{myc}$ in human P-493 B lymphoma cells and PC3 prostate cancer cells [158]. p53 can bind to its response element present in miR-145 promoter and can up regulate miR-145 expression. Since miR145 directly targets the $3^{\prime}$ UTR of c-myc gene, it is likely that p53 can regulate c-myc expression via miR-145 [159].

3.2. Cyclin D1. Cyclin D1 is widely accepted gene in the contribution of oncogenesis of various cancerous cells, and the increased levels of cyclin D1 and c-myc in mouse breast cancer showed enhanced level of invasion and metastasis [154]. Additionally, cyclin D1, which upon genomic rearrangement, forms clonal lesions by overexpression in multiple types of cancers [160]. The highly conserved cluster of miR-17-92 acts as a negative regulator of cell proliferation. They sequentially are involved in the regulation of cyclin D1 [113] and are regulated by c-myc via E-boxes in the promoter [161] whose dysregulation results in tumor. A research on the regulatory feedback of miRNA 17/20 suggested that miR-17$5 \mathrm{p} / \mathrm{miR}-20$ a down regulates cyclin D1 in human breast cancer and their cell lines resulted in inhibition of serum-induced $S$ phase entry, while in mammary epithelial cells cyclin D1 after sufficient transcription induces the expression of miR17 and miR-20 forming a cluster which results in a feedback loop which in turn limits cell proliferation [113]. In a gene target prediction study, it was notably identified that miR$193 \mathrm{~b}$ in melanoma cell lines down regulates around 18 genes. One among these genes is cyclin D1. This prediction can stand as a basis for the study of the role of miR-193b in breast cancer [162]. miR-200 is a family of miRNA that regulates cyclin D1 indirectly. It was identified that in HeLa cells miR$200 \mathrm{~b}$ binds to the $3^{\prime}$ UTR of RND3 directly and reduces its expression transcriptionally and translationally. This in turn upregulated cyclin D1 protein expression and increased S phase entry [163]. Besides, the up regulation of miR-98 and miR-21 is known to decrease the expression of c-myc and E2F2 proteins through estrogen receptor $\alpha$ [164], and they act as tumor suppressors. miR-503 is known to act as putative tumor suppressor, and it targets cyclin D1 [165].

3.3. Runx2. There are several transcription factors being implicated with cancer progression. The transcription factor Runx 2 has an established role in cancers that metastasize to bone. Runx 2 is critical for regulation of genes that support bone formation and is abnormally expressed in tumors that metastasize to bone. The Runx genes comprise a family of 
three closely related transcription factors: Runx1, Runx2, and Runx3, which together with a common partner $(\mathrm{CBF} \beta)$ form the core binding factor (CBF) complex and bind DNA to either activate or repress gene transcription. While Runxl and Runx3 mutations are linked with leukemia and gastric cancer, respectively [166, 167], Runx 2 has been proposed as one of the pivotal factors in the process of osteogenesis and metastasis in human malignancies including breast cancer [18-20]. Runx2 can function as a metastasis-related oncoprotein in nonosseous cancer cells [168]. In normal mammary epithelial cells Runx2 is expressed at low levels, but it is expressed at high levels in metastatic breast cancer cells $[169,170]$. It is now widely recognized that breast cancer cells preferentially metastasize to bone $[50,171]$. It has shown that inhibition of Runx 2 activity abolishes the ability of breast cancer cells to form osteolytic lesions in vivo [50]. Furthermore, perturbation of Runx2 subnuclear localization in breast cancer cells inhibits formation of osteolytic lesions in bone in vivo.

It was proposed that Runx2 activates cancer related genes in response to deregulated cell signaling pathways during early stages of breast cancer. In recent years, several miRNAs have been identified which can target Runx2. For example, miR-155 and miR-355 directly target Runx2 [172, 173]. miR155 targets the $3^{\prime}$ untranslated region of multiple components of the BMP signaling cascade, including SMAD1, SMAD5, HIVEP2, CEBPB, Runx2, and MYO10. miR-155 is expressed at elevated levels in human cancers including cancers of the lung, breast, colon, and a subset of lymphoid malignancies [50]. Runx2 expression can be downregulated by miRNAs such as miR-133, miR-204/211 [174, 175]. It is evident that the role of Runx 2 is associated with breast cancer mediated bone metastasis [50]. Understanding miRNAs that regulate Runx2 activity supporting transformation of normal cells to bone metastatic cancer cells would provide options for therapeutic targets. The role of miR-106b was determined in regulating Runx2, Cyclin D1, and myc via Wnt pathway with $\beta$-catenin over expression. Also the reduced expression level of Cyclin D1 by miR-145 via ESR-1 endorsed the fact that the gene supports cell cycle progression [176]. In silico validation identified that miR-296 disrupts the EGFR signaling [177]. Runx2 promotes differentiation of osteoblasts in wild type with regulation of various cyclins. The up regulation of Runx 2 during early $\mathrm{G} 1$ and down regulation prior to $\mathrm{S}$ phase indicate its role in cell proliferation [178-180].

Runx2 is functionally coupled with the cell motility in MDA-MB-231 cells. This shows its role in the metastatic potential of breast cancer cells with its capability to promote invasiveness and osteolytic property through a set of genes required for cell adhesion and motility by gain of function effect $[180,181]$. Osteogenesis can be negatively regulated by miR-204 and miR-211 in mesenchymal progenitor and BMSCs. The repression of osteogenesis process could be due to binding of miR-204/211 to the $3^{\prime}$-UTR of Runx 2 gene [174]. It is reported that Runx2 stimulates Cyclin D1 and reduces apoptosis by a synergy between Runx 2 and c-myc $[180,182]$. miR-204, 205, 217, 133, and 135 were downregulated in osteogenesis while miR-133, 135, 137, 204, 205, 217, and 218 were upregulated during chondrogenesis, and these miRNAs are recorded to regulate Runx2 [18]. The regulatory mechanism of miRNAs by Runx 2 was identified in osteoblast differentiation with the formation of Runx $2 / \mathrm{miR}$ 3960/miR-2861 feedback loop. miR-3960 regulates the BMP2 induced osteogenesis by targeting the Hoxa2, a repressor of Runx2 [183]. Eventhough it is evident that the role of Runx2 is associated with breast cancer mediated bone metastasis, further studies are needed to explore the miRNA expression profile targeting Runx2 in primary breast cancer growth and bone metastasis. These studies suggest that the up- or downregulation of one or more miRNAs would be a valid approach to alter expression of c-Myc, Cyclin D1, and Runx2 genes, thereby prohibiting breast cancer progression to bone metastasis.

\section{Conclusions and Future Perspectives}

miRNAs are emerging group of ribonucleotides, and studies on miRNAs and their expression are supportive for better understanding of the network of genes and cellular pathways regulated by these miRNAs. Recently, the increased numbers of miRNAs' analysis and their multiple target validation in different contexts of breast cancer are attaining a strong insight in the field of miRNA based diagnosis and therapy for breast cancer and bone metastasis. There is differential expression and regulation of miRNAs associated with breast cancer growth and bone metastasis, which would help identifying them as possible biomarkers. Potential therapies such as miRNA silencing, antisense blocking, miRNA modifications, or over-expression of miRNAs may be considered, and they would provide new opening avenues for more treatment strategies for patients with breast cancer and bone metastasis. Before stepping into miRNA based diagnosis and treatment of breast cancer, miRNA experimental expression tool and oligonucleotides strategies should be further developed. miRNA based therapy for breast cancer and bone metastasis requires clinical evaluation of preferred miRNAs' actions at various levels. Prior to systemic administration, clinical trial is important to determine their exclusive targets, site specificity, and dose requirement. The synthetic miRNAs require chemical modification(s) so that they can be stable in systems' fluid and can also be tissue specific. Delivery of miRNAs to a specific tissue would also require an appropriate, nontoxic, degradable delivery system. Thus, the maximized drug activity and the minimized side effects like toxicity and antigenicity should be considered for utilization of miRNAs in breast cancer therapy.

\section{Acknowledgment}

This work was supported by grants from Indian Council of Medical Research, India (5/13/2009-NCD-III; 80/10/2010BMS to N. Selvamurugan).

\section{References}

[1] "Male breast cancer is a disease in which malignant (cancer) cells form in the tissues of the breast," National Cancer Institute, 2013. 
[2] "What Are the Key Statistics About Breast Cancer in Men?" American Cancer Society, 2007.

[3] C. Desantis, R. Siegel, P. Bandi, and A. Jemal, "Breast cancer statistics, 2011," CA Cancer Journal for Clinicians, vol. 61, no. 6, pp. 409-418, 2011.

[4] Y. Kang, P. M. Siegel, W. Shu et al., "A multigenic program mediating breast cancer metastasis to bone," Cancer Cell, vol. 3, no. 6, pp. 537-549, 2003.

[5] S. L. Davis, S. G. Eckhardt, W. A. Messersmith, and A. Jimeno, "The development of regorafenib and its current and potential future role in cancer therapy," Drugs of Today, vol. 49, pp. 105115, 2013.

[6] R. Kumar, J. M. Herman, C. L. Wolfgang, and L. Zheng, "Multidisciplinary management of pancreatic cancer," Surgical Oncology Clinics of North America, vol. 22, pp. 265-287, 2013.

[7] S. Moore, "Managing treatment side effects in advanced breast cancer," Seminars in Oncology Nursing, vol. 23, no. 2, pp. S23S30, 2007.

[8] T. A. Buchholz, "Radiation therapy for early-stage breast cancer after breast-conserving surgery," The New England Journal of Medicine, vol. 360, no. 1, pp. 63-70, 2009.

[9] C. K. Zoon, E. Q. Starker, A. M. Wilson, M. R. Emmert-Buck, S. K. Libutti, and M. A. Tangrea, "Current molecular diagnostics of breast cancer and the potential incorporation of microRNA," Expert Review of Molecular Diagnostics, vol. 9, no. 5, pp. 455466, 2009.

[10] M. V. Iorio, M. Ferracin, C.-G. Liu et al., "MicroRNA gene expression deregulation in human breast cancer," Cancer Research, vol. 65, no. 16, pp. 7065-7070, 2005.

[11] R. I. Gregory, T. P. Chendrimada, and R. Shiekhattar, "MicroRNA biogenesis: isolation and characterization of the microprocessor complex," Methods in Molecular Biology, vol. 342, pp. 3347, 2006.

[12] E. P. Murchison and G. J. Hannon, "miRNAs on the move: miRNA biogenesis and the RNAi machinery," Current Opinion in Cell Biology, vol. 16, no. 3, pp. 223-229, 2004.

[13] A. Grishok, A. E. Pasquinelli, D. Conte et al., "Genes and mechanisms related to RNA interference regulate expression of the small temporal RNAs that control C. elegans developmental timing," Cell, vol. 106, no. 1, pp. 23-34, 2001.

[14] G. D. Bossé and M. J. Simard, "A new twist in the microRNA pathway: not dicer but argonaute is required for a microRNA production," Cell Research, vol. 20, no. 7, pp. 735-737, 2010.

[15] D. Cifuentes, H. Xue, D. W. Taylor et al., "A novel miRNA processing pathway independent of dicer requires argonaute 2 catalytic activity," Science, vol. 328, no. 5986, pp. 1694-1698, 2010.

[16] D. Sayed and M. Abdellatif, "MicroRNAs in development and disease," Physiological Reviews, vol. 91, pp. 827-887, 2011.

[17] T. Kawamata, M. Yoda, and Y. Tomari, "Multilayer checkpoints for microRNA authenticity during RISC assembly," $E M B O$ Reports, vol. 12, no. 9, pp. 944-949, 2011.

[18] J. B. Lian, G. S. Stein, A. J. Van Wijnen et al., "MicroRNA control of bone formation and homeostasis," Nature Reviews Endocrinology, vol. 8, no. 4, pp. 212-227, 2012.

[19] S. Vimalraj and N. Selvamurugan, "MicroRNAs: synthesis, gene regulation and osteoblast differentiation," Current Issues in Molecular Biology, vol. 15, pp. 7-18, 2012.

[20] A. Moorthi, S. Vimalraj, C. Avani, Z. He, N. C. Partridge, and N. Selvamurugan, "Expression of microRNA-30c and its target genes in human osteoblastic cells by nano-bioglass ceramictreatment," International Journal of Biological Macromolecules, vol. 56, pp. 181-185, 2013.

[21] J. R. Lytle, T. A. Yario, and J. A. Steitz, “Target mRNAs are repressed as efficiently by microRNA-binding sites in the $5^{\prime}$ UTR as in the $3^{\prime}$ UTR," Proceedings of the National Academy of Sciences of the United States of America, vol. 104, no. 23, pp. 9667-9672, 2007.

[22] I. Lee, S. S. Ajay, I. Y. Jong et al., "New class of microRNA targets containing simultaneous $5^{\prime}$-UTR and $3^{\prime}$-UTR interaction sites," Genome Research, vol. 19, no. 7, pp. 1175-1183, 2009.

[23] J. Brennecke, A. Stark, R. B. Russell, and S. M. Cohen, "Principles of microRNA-target recognition," PLoS Biology, vol. 3, no. 3, article e85, 2005.

[24] P. Mestdagh, S. Lefever, F. Pattyn et al., "The microRNA body map: dissecting microRNA function through integrative genomics," Nucleic Acids Research, vol. 39, no. 20, article e136, 2011.

[25] S. Zhu, M.-L. Si, H. Wu, and Y.-Y. Mo, "MicroRNA-21 targets the tumor suppressor gene tropomyosin 1 (TPM1)," Journal of Biological Chemistry, vol. 282, no. 19, pp. 14328-14336, 2007.

[26] J. Boyd, J. I. Risinger, R. W. Wiseman, B. A. Merrick, J. K. Selkirk, and J. C. Barrett, "Regulation of microfilament organization and anchorage-independent growth by tropomyosin 1," Proceedings of the National Academy of Sciences of the United States of America, vol. 92, no. 25, pp. 11534-11538, 1995.

[27] L. Qi, J. Bart, L. P. Tan et al., "Expression of miR-21 and its targets (PTEN, PDCD4, TM1) in flat epithelial atypia of the breast in relation to ductal carcinoma in situ and invasive carcinoma," BMC Cancer, vol. 9, article 163, 2009.

[28] I. Sansal and W. R. Sellers, "The biology and clinical relevance of the PTEN tumor suppressor pathway," Journal of Clinical Oncology, vol. 22, no. 14, pp. 2954-2963, 2004.

[29] H.-S. Yang, A. P. Jansen, R. Nair et al., "A novel transformation suppressor, Pdcd4, inhibits AP-1 transactivation but not NF- $\kappa \mathrm{B}$ or ODC transactivation," Oncogene, vol. 20, no. 6, pp. 669-676, 2001.

[30] L. B. Frankel, N. R. Christoffersen, A. Jacobsen, M. Lindow, A. Krogh, and A. H. Lund, "Programmed cell death 4 (PDCD4) is an important functional target of the microRNA miR-21 in breast cancer cells," Journal of Biological Chemistry, vol. 283, no. 2, pp. 1026-1033, 2008.

[31] B. Lankat-Buttgereit and R. Göke, "The tumour suppressor Pdcd4: recent advances in the elucidation of function and regulation," Biology of the Cell, vol. 101, no. 6, pp. 309-317, 2009.

[32] M. Terao, M. Fratelli, M. Kurosaki et al., "Induction of miR-21 by retinoic acid in estrogen receptor-positive breast carcinoma cells: biological correlates and molecular targets," Journal of Biological Chemistry, vol. 286, no. 5, pp. 4027-4042, 2011.

[33] L. Chen, Y. Li, Y. Fu et al., "Role of deregulated microRNAs in breast cancer progression using FFPE tissue," PLoS ONE, vol. 8, Article ID e54213, 2013.

[34] A. Ozgun, B. Karagoz, O. Bilgi, T. Tuncel, H. Baloglu, and E. G. Kandemir, "MicroRNA-21 as an indicator of aggressive phenotype in breast cancer," Onkologie, vol. 36, pp. 115-118, 2013.

[35] L. X. Yan, Q. N. Wu, Y. Zhang et al., "Knockdown of miR-21 in human breast cancer cell lines inhibits proliferation, in vitro migration and in vivo tumor growth," Breast Cancer Research, vol. 13, no. 1, article R, 2011. 
[36] F. Pichiorri, D. Palmieri, L. De Luca et al., "In vivo NCL targeting affects breast cancer aggressiveness through miRNA regulation," Journal of Experimental Medicine, vol. 210, pp. 951-968, 2013.

[37] L. Ma, J. Teruya-Feldstein, and R. A. Weinberg, "Tumour invasion and metastasis initiated by microRNA-10b in breast cancer," Nature, vol. 449, no. 7163, pp. 682-688, 2007.

[38] L. Ma, "Role of miR-10b in breast cancer metastasis," Breast Cancer Research, vol. 12, no. 5, article 210, 2010.

[39] M. Negrini and G. A. Calin, "Breast cancer metastasis: a microRNA story," Breast Cancer Research, vol. 10, no. 2, article 303, 2008.

[40] F. Biagioni, N. Bossel Ben-Moshe, G. Fontemaggi et al., "miR$10 \mathrm{~b}^{*}$, a master inhibitor of the cell cycle, is down-regulated in human breast tumours," EMBO Molecular Medicine, vol. 4, pp. 1214-1229, 2012.

[41] S. A. Ibrahim, G. W. Yip, C. Stock et al., "Targeting of syndecan1 by microRNA miR-10b promotes breast cancer cell motility and invasiveness via a Rho-GTPase- and E-cadherin-dependent mechanism," International Journal of Cancer, vol. 131, pp. E884E896, 2012.

[42] G. K. Scott, A. Goga, D. Bhaumik, C. E. Berger, C. S. Sullivan, and C. C. Benz, "Coordinate suppression of ERBB2 and ERBB3 by enforced expression of micro-RNA miR-125a or miR-125b," Journal of Biological Chemistry, vol. 282, no. 2, pp. 1479-1486, 2007.

[43] M. D. Mattie, C. C. Benz, J. Bowers et al., "Optimized highthroughput microRNA expression profiling provides novel biomarker assessment of clinical prostate and breast cancer biopsies," Molecular Cancer, vol. 5, article 24, 2006.

[44] Y. Zhang, J.-S. Gao, X. Tang et al., "MicroRNA 125a and its regulation of the p53 tumor suppressor gene," FEBS Letters, vol. 583, no. 22, pp. 3725-3730, 2009.

[45] E. O’Day and A. Lal, "MicroRNAs and their target gene networks in breast cancer," Breast Cancer Research, vol. 12, no. 2, article 201, 2010.

[46] W. Kong, H. Yang, L. He et al., "MicroRNA-155 is regulated by the transforming growth factor $\beta /$ Smad pathway and contributes to epithelial cell plasticity by targeting RhoA," Molecular and Cellular Biology, vol. 28, no. 22, pp. 6773-6784, 2008.

[47] W. Kong, L. He, M. Coppola et al., "MicroRNA-155 regulates cell survival, growth, and chemosensitivity by targeting FOXO3a in breast cancer," Journal of Biological Chemistry, vol. 285, no. 23, pp. 17869-17879, 2010.

[48] S. Jiang, L.-F. Zhang, H.-W. Zhang et al., "A novel miR-155/miR143 cascade controls glycolysis by regulating hexokinase 2 in breast cancer cells," EMBO Journal, vol. 31, no. 8, pp. 1985-1998, 2012.

[49] C. Roth, B. Rack, V. Müller, W. Janni, K. Pantel, and H. Schwarzenbach, "Circulating microRNAs as blood-based markers for patients with primary and metastatic breast cancer," Breast Cancer Research, vol. 12, no. 6, article R90, 2010.

[50] Q. Yin, X. Wang, C. Fewell et al., "MicroRNA miR-155 inhibits Bone Morphogenetic Protein (BMP) signaling and BMPmediated Epstein-Barr virus reactivation," Journal of Virology, vol. 84, no. 13, pp. 6318-6327, 2010.

[51] C. Zhang, J. Zhao, and H. Deng, "17 $\beta$-Estradiol up-regulates miR-155 expression and reduces TP53INP1 expression in MCF7 breast cancer cells," Molecular and Cellular Biochemistry, vol. 379, pp. 201-211, 2013.
[52] J. Liu, Q. Mao, Y. Liu, X. Hao, S. Zhang, and J. Zhang, "Analysis of miR-205 and miR-155 expression in the blood of breast cancer patients," Chinese Journal of Cancer Research, vol. 25, pp. 46-54, 2013.

[53] M. I. Rather, M. N. Nagashri, S. S. Swamy, K. S. Gopinath, and A. Kumar, "Oncogenic microRNA-155 down-regulates tumor suppressor CDC73 and promotes oral squamous cell carcinoma cell proliferation: implications for cancer therapeutics," The Journal of Biological Chemistry, vol. 288, pp. 608-618, 2013.

[54] W. Kong, L. He, E. J. Richards et al., "Upregulation of miRNA155 promotes tumour angiogenesis by targeting VHL and is associated with poor prognosis and triple-negative breast cancer," Oncogene, 2013.

[55] Q. Pan, X. Luo, and N. Chegini, "microRNA 21: response to hormonal therapies and regulatory function in leiomyoma, transformed leiomyoma and leiomyosarcoma cells," Molecular Human Reproduction, vol. 16, no. 3, Article ID gap093, pp. 215227, 2009.

[56] G. Gabriely, T. Wurdinger, S. Kesari et al., "MicroRNA 21 promotes glioma invasion by targeting matrix metalloproteinase regulators," Molecular and Cellular Biology, vol. 28, no. 17, pp. 5369-5380, 2008.

[57] S. Zhu, H. Wu, F. Wu, D. Nie, S. Sheng, and Y.-Y. Mo, "MicroRNA-21 targets tumor suppressor genes in invasion and metastasis," Cell Research, vol. 18, no. 3, pp. 350-359, 2008.

[58] I. A. Asangani, S. A. K. Rasheed, D. A. Nikolova et al., "MicroRNA-21 (miR-21) post-transcriptionally downregulates tumor suppressor Pdcd4 and stimulates invasion, intravasation and metastasis in colorectal cancer," Oncogene, vol. 27, no. 15, pp. 2128-2136, 2008.

[59] A. Zhang, Y. Liu, Y. Shen, Y. Xu, and X. Li, "MiR-21 modulates cell apoptosis by targeting multiple genes in renal cell carcinoma," Urology, vol. 78, no. 2, pp. 474.e13-474.e19, 2011.

[60] P. Wang, F. Zou, Z. Xiaodong et al., "microRNA-21 negatively regulates Cdc25A and cell cycle progression in colon cancer cells," Cancer Research, vol. 69, no. 20, pp. 8157-8165, 2009.

[61] Y. Chen, W. Liu, T. Chao et al., "MicroRNA-21 down-regulates the expression of tumor suppressor PDCD4 in human glioblastoma cell T98G," Cancer Letters, vol. 272, no. 2, pp. 197-205, 2008.

[62] F. Loayza-Puch, Y. Yoshida, T. Matsuzaki, C. Takahashi, H. Kitayama, and M. Noda, "Hypoxia and RAS-signaling pathways converge on, and cooperatively downregulate, the RECK tumor-suppressor protein through microRNAs," Oncogene, vol. 29, no. 18, pp. 2638-2648, 2010.

[63] M. Liu, H. Wu, T. Liu et al., "Regulation of the cell cycle gene, BTG2, by miR-21 in human laryngeal carcinoma," Cell Research, vol. 19, no. 7, pp. 828-837, 2009.

[64] S. Roy, S. Khanna, S.-R. A. Hussain et al., "MicroRNA expression in response to murine myocardial infarction: MiR-21 regulates fibroblast metalloprotease-2 via phosphatase and tensin homologue," Cardiovascular Research, vol. 82, no. 1, pp. 21-29, 2009.

[65] G. Song, A. D. Sharma, G. R. Roll et al., "MicroRNAs control hepatocyte proliferation during liver regeneration," Hepatology, vol. 51, no. 5, pp. 1735-1743, 2010.

[66] R. T. Marquez, E. Wendlandt, C. S. Galle, K. Keck, and A. P. McCaffrey, "MicroRNA-21 is upregulated during the proliferative phase of liver regeneration, targets Pellino-1, and inhibits NF- $\kappa$ B signaling," American Journal of Physiology, vol. 298, no. 4, pp. G535-G541, 2010. 
[67] T. Melkamu, X. Zhang, J. Tan, Y. Zeng, and F. Kassie, "Alteration of microRNA expression in vinyl carbamate-induced mouse lung tumors and modulation by the chemopreventive agent indole-3-carbinol," Carcinogenesis, vol. 31, no. 2, pp. 252-258, 2010.

[68] C. Liu, B. Li, Y. Cheng et al., "MiR-21 plays an important role in radiation induced carcinogenesis in $\mathrm{BALB} / \mathrm{c}$ mice by directly targeting the tumor suppressor gene Big-h3," International Journal of Biological Sciences, vol. 7, no. 3, pp. 347-363, 2011.

[69] S. Hu, M. Huang, P. K. Nguyen et al., "Novel MicroRNA prosurvival cocktail for improving engraftment and function of cardiac progenitor cell transplantation," Circulation, vol. 124, no. 11, pp. S27-S34, 2011.

[70] Y. Tian, A. Luo, Y. Cai et al., "MicroRNA-10b promotes migration and invasion through KLF4 in human esophageal cancer cell lines," Journal of Biological Chemistry, vol. 285, no. 11, pp. 7986-7994, 2010.

[71] S. Meseguer, G. Mudduluru, J. M. Escamilla, H. Allgayer, and D. Barettino, "MicroRNAs-10a and $-10 \mathrm{~b}$ contribute to retinoic acid-induced differentiation of neuroblastoma cells and target the alternative splicing regulatory factor SFRS1 (SF2/ASF)," Journal of Biological Chemistry, vol. 286, no. 6, pp. 4150-4164, 2011.

[72] H. Wu, S. Zhu, and Y.-Y. Mo, "Suppression of cell growth and invasion by miR-205 in breast cancer," Cell Research, vol. 19, no. 4, pp. 439-448, 2009.

[73] X. Guo, Y. Wu, and R. S. Hartley, "MicroRNA-125a represses cell growth by targeting HuR in breast cancer," RNA Biology, vol. 6, no. 5, pp. 575-583, 2009.

[74] K. D. Cowden Dahl, R. Dahl, J. N. Kruichak, and L. G. Hudson, "The epidermal growth factor receptor responsive miR-125a represses mesenchymal morphology in ovarian cancer cells," Neoplasia, vol. 11, no. 11, pp. 1208-1215, 2009.

[75] X.-B. Shi, L. Xue, J. Yang et al., "An androgen-regulated miRNA suppresses Bak1 expression and induces androgen-independent growth of prostate cancer cells," Proceedings of the National Academy of Sciences of the United States of America, vol. 104, no. 50, pp. 19983-19988, 2007.

[76] L. Shi, J. Zhang, T. Pan et al., "MiR-125b is critical for the suppression of human U251 glioma stem cell proliferation," Brain Research, vol. 1312, pp. 120-126, 2010.

[77] E. Ferretti, E. De Smaele, E. Miele et al., "Concerted microRNA control of Hedgehog signalling in cerebellar neuronal progenitor and tumour cells," EMBO Journal, vol. 27, no. 19, pp. 26162627, 2008.

[78] J.-H. Klusmann, Z. Li, K. Böhmer et al., "miR-125b-2 is a potential oncomiR on human chromosome 21 in megakaryoblastic leukemia," Genes and Development, vol. 24, no. 5, pp. 478-490, 2010.

[79] M. T. N. Le, N. Shyh-Chang, S. L. Khaw et al., "Conserved regulation of p53 network dosage by microRNA-125b occurs through evolving miRNA-target gene pairs," PLoS Genetics, vol. 7, no. 9, Article ID e1002242, 2011.

[80] H.-F. Xia, T.-Z. He, C.-M. Liu et al., "MiR-125b expression affects the proliferation and apoptosis of human glioma cells by targeting Bmf," Cellular Physiology and Biochemistry, vol. 23, no. 4-6, pp. 347-358, 2009.

[81] P. Sætrom, J. Biesinger, S. M. Li et al., "A risk variant in an miR$125 \mathrm{~b}$ binding site in BMPR1B is associated with breast cancer pathogenesis," Cancer Research, vol. 69, no. 18, pp. 7459-7465, 2009.
[82] X. Guo, Y. Wu, and R. S. Hartley, "MicroRNA-125a represses cell growth by targeting HuR in breast cancer," RNA Biology, vol. 6, no. 5, pp. 575-583, 2009.

[83] A. J. Murphy, P. M. Guyre, and P. A. Pioli, "Estradiol suppresses NF- $\kappa$ B activation through coordinated regulation of let-7a and miR-125b in primary human macrophages," Journal of Immunology, vol. 184, no. 9, pp. 5029-5037, 2010.

[84] L. Huang, J. Luo, Q. Cai et al., "MicroRNA-125b suppresses the development of bladder cancer by targeting E2F3," International Journal of Cancer, vol. 128, no. 8, pp. 1758-1769, 2011.

[85] M. Bousquet, D. Nguyen, C. Chen, L. Shields, and H. F. Lodish, "MicroRNA-125b transforms myeloid cell lines by repressing multiple mRNA," Haematologica, vol. 97, pp. 1713-1721, 2012.

[86] M. T. N. Le, N. Shyh-Chang, S. L. Khaw et al., "Conserved regulation of p53 network dosage by microRNA-125b occurs through evolving miRNA-target gene pairs," PLoS Genetics, vol. 7, no. 9, Article ID e1002242, 2011.

[87] Y. Zhang, Z. Diao, L. Su et al., "MicroRNA-155 contributes to preeclampsia by down-regulating CYR61," American Journal of Obstetrics and Gynecology, vol. 202, no. 5, pp. 466.el-466.e7, 2010.

[88] S. Jiang, H.-W. Zhang, M.-H. Lu et al., "MicroRNA-155 functions as an oncomiR in breast cancer by targeting the suppressor of cytokine signaling 1 gene," Cancer Research, vol. 70, no. 8, pp. 3119-3127, 2010.

[89] Q. Jiang, M.-G. Feng, and Y.-Y. Mo, "Systematic validation of predicted microRNAs for cyclin D1," BMC Cancer, vol. 9, article 194, 2009.

[90] B. Xiao, Z. Liu, B.-S. Li et al., "Induction of microRNA-155 during helicobacter pylori infection and its negative regulatory role in the inflammatory response," Journal of Infectious Diseases, vol. 200, no. 6, pp. 916-925, 2009.

[91] M. T. Bolisetty, G. Dy, W. Tam, and K. L. Beemon, "Reticuloendotheliosis virus strain $\mathrm{T}$ induces miR-155, which targets JARID2 and promotes cell survival," Journal of Virology, vol. 83, no. 23, pp. 12009-12017, 2009.

[92] M. He, Z. Xu, T. Ding, D.-M. Kuang, and L. Zheng, "MicroRNA155 regulates inflammatory cytokine production in tumorassociated macrophages via targeting C/EBP $\beta$," Chinese Journal of Cellular and Molecular Immunology, vol. 6, no. 5, pp. 343-352, 2009.

[93] I. M. Pedersen, D. Otero, E. Kao et al., "Onco-miR-155 targets SHIP1 to promote TNF $\alpha$-dependent growth of B cell lymphomas," EMBO Molecular Medicine, vol. 1, no. 5, pp. 288-295, 2009.

[94] E. Zonari, F. Pucci, M. Saini et al., "A role for miR-155 in enabling tumor-infiltrating innate immune cells to mount effective antitumor responses in mice," Blood, vol. 122, pp. 243-252, 2013.

[95] M. F. Czyzyk-Krzeska and X. Zhang, "MiR-155 at the heart of oncogenic pathways," Oncogene, 2013.

[96] P. M. Neilsen, J. E. Noll, S. Mattiske et al., "Mutant p53 drives invasion in breast tumors through up-regulation of miR-155," Oncogene, vol. 32, pp. 2992-3000, 2012.

[97] M. M. Hafez, Z. K. Hassan, A. R. Zekri et al., "MicroRNAs and metastasis-related gene expression in Egyptian breast cancer patients," Asian Pacific Journal of Cancer Prevention, vol. 13, pp. 591-598, 2012.

[98] B. D. Adams, H. Furneaux, and B. A. White, "The microribonucleic acid (miRNA) miR-206 targets the human estrogen receptor- $\alpha(\mathrm{ER} \alpha)$ and represses $\mathrm{ER} \alpha$ messenger RNA and protein expression in breast cancer cell lines," Molecular Endocrinology, vol. 21, no. 5, pp. 1132-1147, 2007. 
[99] N. Kondo, T. Toyama, H. Sugiura, Y. Fujii, and H. Yamashita, "miR-206 expression is down-regulated in estrogen receptor $\alpha$ positive human breast cancer," Cancer Research, vol. 68, no. 13, pp. 5004-5008, 2008.

[100] R. García-Becerra, N. Santos, L. Díaz, and J. Camacho, "Mechanisms of resistance to endocrine therapy in breast cancer: focus on signaling pathways, miRNAs and genetically based resistance," International Journal of Molecular Sciences, vol. 14, pp. 108-145, 2012.

[101] M. J. Lee, K. S. Yoon, K. W. Cho, K. S. Kim, and H. S. Jung, "Expression of miR-206 during the initiation of mammary gland development," Cell and Tissue Research, vol. 353, no. 3, pp. 425-433, 2013.

[102] J. Zhou, Y. Tian, J. Li et al., "miR-206 is down-regulated in breast cancer and inhibits cell proliferation through the upregulation of cyclinD2," Biochemical and Biophysical Research Communications, vol. 433, pp. 207-212, 2013.

[103] S. Valastyan, F. Reinhardt, N. Benaich et al., "A pleiotropically acting MicroRNA, miR-31, inhibits breast cancer metastasis," Cell, vol. 137, no. 6, pp. 1032-1046, 2009.

[104] O. Aprelikova, X. Yu, J. Palla et al., "The role of miR-31 and its target gene SATB2 in cancer-associated fibroblasts," Cell Cycle, vol. 9, no. 21, pp. 4387-4398, 2010.

[105] R. Rouas, H. Fayyad-Kazan, N. El Zien et al., "Human natural Treg microRNA signature: role of microRNA-31 and microRNA-21 in FOXP3 expression," European Journal of Immunology, vol. 39, no. 6, pp. 1608-1618, 2009.

[106] Y. T. Chan, Y. C. Lin, R. J. Lin et al., "Concordant and discordant regulation of target genes by miR-31 and its isoforms," PLoS ONE, vol. 8, Article ID e58169, 2013.

[107] C. Korner, I. Keklikoglou, C. Bender, A. Worner, E. Münstermann, and S. Wiemann, "MicroRNA-31 sensitizes human breast cells to apoptosis by direct targeting of protein kinase $\mathrm{C}$ epsilon (PKCepsilon)," The Journal of Biological Chemistry, vol. 288, pp. 8750-8761, 2013.

[108] D. R. Hurst, M. D. Edmonds, G. K. Scott, C. C. Benz, K. S. Vaidya, and D. R. Welch, "Breast cancer metastasis suppressor 1 up-regulates miR-146, Which suppresses breast cancer metastasis," Cancer Research, vol. 69, no. 4, pp. 1279-1283, 2009.

[109] Y. Tang, X. Luo, H. Cui et al., "MicroRNA-146a contributes to abnormal activation of the type I interferon pathway in human lupus by targeting the key signaling proteins," Arthritis and Rheumatism, vol. 60, no. 4, pp. 1065-1075, 2009.

[110] D. Bhaumik, G. K. Scott, S. Schokrpur, C. K. Patil, J. Campisi, and C. C. Benz, "Expression of microRNA-146 suppresses NF$\kappa \mathrm{B}$ activity with reduction of metastatic potential in breast cancer cells," Oncogene, vol. 27, no. 42, pp. 5643-5647, 2008.

[111] G. Eiriksdottir, G. Johannesdottir, S. Ingvarsson et al., "Mapping loss of heterozygosity at chromosome 13q: loss at 13q12-q13 is associated with breast turnout progression and poor prognosis," European Journal of Cancer, vol. 34, no. 13, pp. 2076-2081, 1998.

[112] A. Hossain, M. T. Kuo, and G. F. Saunders, "Mir-17-5p regulates breast cancer cell proliferation by inhibiting translation of AIB1 mRNA," Molecular and Cellular Biology, vol. 26, no. 21, pp. 81918201, 2006.

[113] Z. Yu, C. Wang, M. Wang et al., "A cyclin D1/microRNA $17 / 20$ regulatory feedback loop in control of breast cancer cell proliferation," Journal of Cell Biology, vol. 182, no. 3, pp. 509$517,2008$.

[114] Z. Yu, N. E. Willmarth, J. Zhou et al., "microRNA 17/20 inhibits cellular invasion and tumor metastasis in breast cancer by heterotypic signaling," Proceedings of the National Academy of Sciences of the United States of America, vol. 107, no. 18, pp. 82318236, 2010.

[115] S.-K. Leivonen, R. Mäkelä, P. Östling et al., "Protein lysate microarray analysis to identify microRNAs regulating estrogen receptor signaling in breast cancer cell lines," Oncogene, vol. 28, no. 44, pp. 3926-3936, 2009.

[116] D. Yan, X. D. Dong, X. Chen et al., "MicroRNA-1/206 targets cmet and inhibits rhabdomyosarcoma development," Journal of Biological Chemistry, vol. 284, no. 43, pp. 29596-29604, 2009.

[117] G. Song, Y. Zhang, and L. Wang, "MicroRNA-206 targets notch3, activates apoptosis, and inhibits tumor cell migration and focus formation," Journal of Biological Chemistry, vol. 284, no. 46, pp. 31921-31927, 2009.

[118] C.-J. Liu, M.-M. Tsai, P.-S. Hung et al., "miR-31 ablates expression of the HIF regulatory factor FIH to activate the HIF pathway in head and neck carcinoma," Cancer Research, vol. 70, no. 4, pp. 1635-1644, 2010.

[119] C. Labbaye, I. Spinello, M. T. Quaranta et al., "A three-step pathway comprising PLZF/miR-146a/CXCR4 controls megakaryopoiesis," Nature Cell Biology, vol. 10, no. 7, pp. 788-801, 2008.

[120] C.-H. Hsieh, C.-S. Rau, S.-F. Jeng et al., "Identification of the potential target genes of microRNA-146a induced by PMA treatment in human microvascular endothelial cells," Experimental Cell Research, vol. 316, no. 7, pp. 1119-1126, 2010.

[121] G. Curtale, F. Citarella, C. Carissimi et al., "An emerging player in the adaptive immune response: MicroRNA-146a is a modulator of IL-2 expression and activation-induced cell death in T lymphocytes," Blood, vol. 115, no. 2, pp. 265-273, 2010.

[122] S. Rom, I. Rom, G. Passiatore et al., "CCL8/MCP-2 is a target for mir-146a in HIV-1-infected human microglial cells," FASEB Journal, vol. 24, no. 7, pp. 2292-2300, 2010.

[123] M. Sinha, J. Ghose, E. Das, and N. P. Bhattarcharyya, "Altered microRNAs in STHdhQ111/HdhQ111 cells: miR-146a targets TBP," Biochemical and Biophysical Research Communications, vol. 396, no. 3, pp. 742-747, 2010.

[124] H. Xia, Y. Qi, S. S. Ng et al., "microRNA-146b inhibits glioma cell migration and invasion by targeting MMPs," Brain Research, vol. 1269, pp. 158-165, 2009.

[125] M. V. Iorio, P. Casalini, C. Piovan et al., "MicroRNA-205 regulates HER3 in human breast cancer," Cancer Research, vol. 69, no. 6, pp. 2195-2200, 2009.

[126] T. Holbro, R. R. Beerli, F. Maurer, M. Koziczak, C. F. Barbas III, and N. E. Hynes, “The ErbB2/ErbB3 heterodimer functions as an oncogenic unit: ErbB2 requires ErbB3 to drive breast tumor cell proliferation," Proceedings of the National Academy of Sciences of the United States of America, vol. 100, no. 15, pp. 8933-8938, 2003.

[127] S. B. Greene, J. I. Herschkowitz, and J. M. Rosen, “The ups and downs of miR-205: identifying the roles of miR-205 in mammary gland development and breast cancer," RNA Biology, vol. 7, no. 3, 2010.

[128] J. Y. Lee, M. K. Park, J. H. Park et al., "Loss of the polycomb protein Mel-18 enhances the epithelial-mesenchymal transition by ZEB1 and ZEB2 expression through the downregulation of miR-205 in breast cancer," Oncogene, 2013.

[129] C. Piovan, D. Palmieri, G. Di Leva et al., "Oncosuppressive role of p53-induced miR-205 in triple negative breast cancer," Molecular Oncology, vol. 6, pp. 458-472, 2012.

[130] M. Tanic, M. Zajac, G. Gómez-López, J. Benítez, and B. Martínez-Delgado, "Integration of BRCA1-mediated miRNA 
and mRNA profiles reveals microRNA regulation of TRAF2 and $\mathrm{NF} \kappa \mathrm{B}$ pathway," Breast Cancer Research and Treatment, vol. 134, pp. 41-51, 2012.

[131] X. Li, S. U. Mertens-Talcott, S. Zhang, K. Kim, J. Ball, and S. Safe, "MicroRNA-27a indirectly regulates estrogen receptor $\alpha$ expression and hormone responsiveness in MCF-7 breast cancer cells," Endocrinology, vol. 151, no. 6, pp. 2462-2473, 2010.

[132] S. U. Mertens-Talcott, S. Chintharlapalli, X. Li, and S. Safe, "The oncogenic microRNA-27a targets genes that regulate specificity protein transcription factors and the G2-M checkpoint in MDA-MB-231 breast cancer cells," Cancer Research, vol. 67, no. 22, pp. 11001-11011, 2007.

[133] G. K. Scott, M. D. Mattie, C. E. Berger, S. C. Benz, and C. C. Benz, "Rapid alteration of microRNA levels by histone deacetylase inhibition," Cancer Research, vol. 66, no. 3, pp. 1277-1281, 2006.

[134] K. Gajjar, P. L. Martin-Hirsch, and F. L. . Martin, "CYP1B1 and hormone-induced cancer," Cancer Letters, vol. 324, no. 1, pp. 1330, 2012.

[135] Y. Tsuchiya, M. Nakajima, S. Takagi, T. Taniya, and T. Yokoi, "MicroRNA regulates the expression of human cytochrome P450 1B1," Cancer Research, vol. 66, no. 18, pp. 9090-9098, 2006.

[136] L. Jin, O. Wessely, E. Marcusson, C. Ivan, G. Calin, and S. K. Alahari, "Prooncogenic factors miR-23b and miR-27b are regulated by Her2/Neu, EGF, and TNF- $\alpha$ in breast cancer," Cancer Research, vol. 73, pp. 2884-2896, 2013.

[137] J. T. Buijs, P. Juárez, and T. A. Guise, "Therapeutic strategies to target TGF- $\beta$ in the treatment of bone metastases," Current Pharmaceutical Biotechnology, vol. 12, pp. 2121-2137, 2011.

[138] T. Kim and A. Reitmair, "Non-coding RNAs: functional aspects and diagnostic utility in oncology," International Journal of Molecular Sciences, vol. 14, pp. 4934-4968, 2013.

[139] Y. X. Fang and W. Q. Gao, "Roles of microRNAs during prostatic tumorigenesis and tumor progression," Oncogene, 2013.

[140] J. Tang, A. Ahmad, and F. H. Sarkar, "The role of microRNAs in breast cancer migration, invasion and metastasis," International Journal of Molecular Sciences, vol. 13, pp. 13414-13437, 2012.

[141] J. B. Patel, H. N. Appaiah, R. M. Burnett et al., "Control of EVI-1 oncogene expression in metastatic breast cancer cells through microRNA miR-22," Oncogene, vol. 30, no. 11, pp. 1290-1301, 2011.

[142] S. Valastyan, A. Chang, N. Benaich, F. Reinhardt, and R. A. Weinberg, "Activation of miR-31 function in already-established metastases elicits metastatic regression," Genes and Development, vol. 25, no. 6, pp. 646-659, 2011.

[143] S. F. Tavazoie, C. Alarcón, T. Oskarsson et al., "Endogenous human microRNAs that suppress breast cancer metastasis," Nature, vol. 451, no. 7175, pp. 147-152, 2008.

[144] P. A. Gregory, A. G. Bert, E. L. Paterson et al., "The miR200 family and miR-205 regulate epithelial to mesenchymal transition by targeting ZEB1 and SIP1," Nature Cell Biology, vol. 10, no. 5, pp. 593-601, 2008.

[145] P. Gandellini, M. Folini, N. Longoni et al., "MiR-205 exerts tumor-suppressive functions in human prostate through downregulation of protein kinase CE," Cancer Research, vol. 69, no. 6, pp. 2287-2295, 2009.

[146] S. S. Myatt, J. Wang, L. J. Monteiro et al., "Definition of microRNAs that repress expression of the tumor suppressor gene FOXO1 in endometrial cancer," Cancer Research, vol. 70, no. 1, pp. 367-377, 2010.
[147] Q. Wang, D.-C. Li, Z.-F. Li et al., "Upregulation of miR-27a contributes to the malignant transformation of human bronchial epithelial cells induced by SV40 small T antigen," Oncogene, vol. 30, no. 36, pp. 3875-3886, 2011.

[148] Y. Wang, R. Rathinam, A. Walch, and S. K. Alahari, "ST14 (suppression of tumorigenicity 14) gene is a target for miR-27b, and the inhibitory effect of ST14 on cell growth isindependent of miR-27b regulation," Journal of Biological Chemistry, vol. 284, no. 34, pp. 23094-23106, 2009.

[149] N. Akhtar, Z. Rasheed, S. Ramamurthy, A. N. Anbazhagan, F. R. Voss, and T. M. Haqqi, "MicroRNA-27b regulates the expression of matrix metalloproteinase 13 in human osteoarthritis chondrocytes," Arthritis and Rheumatism, vol. 62, no. 5, pp. 1361-1371, 2010.

[150] W. Tang, J. Zhu, S. Su et al., "MiR-27 as a prognostic marker for breast cancer progression and patient survival," PLOS ONE, vol. 7, Article ID e51702, 2012.

[151] G. Grelier, N. Voirin, A.-S. Ay et al., "Prognostic value of Dicer expression in human breast cancers and association with the mesenchymal phenotype," British Journal of Cancer, vol. 101, no. 4, pp. 673-683, 2009.

[152] S. Liu, R. H. Goldstein, E. M. Scepansky, and M. Rosenblatt, "Inhibition of Rho-associated kinase signaling prevents breast cancer metastasis to human bone," Cancer Research, vol. 69, no. 22, pp. 8742-8751, 2009.

[153] S. Dangi-Garimella, J. Yun, E. M. Eves et al., "Raf kinase inhibitory protein suppresses a metastasis signalling cascade involving LIN28 and let-7," EMBO Journal, vol. 28, no. 4, pp. 347-358, 2009.

[154] C. Wang, Y. Tai, M. P. Lisanti, and D. J. Liao, "c-Myc induction of programmed cell death may contribute to carcinogenesis: a perspective inspired by several concepts of chemical carcinogenesis," Cancer Biology and Therapy, vol. 11, no. 7, pp. 615-626, 2011.

[155] Y. Dorsett, K. M. McBride, M. Jankovic et al., "MicroRNA-155 suppresses activation-induced cytidine deaminase-mediated Myc-Igh translocation," Immunity, vol. 28, no. 5, pp. 630-638, 2008.

[156] A. Lal, F. Navarro, C. A. Maher et al., "miR-24 inhibits cell proliferation by targeting E2F2, MYC, and other cell-cycle genes via binding to "seedless" 3 'UTR MicroRNA recognition elements," Molecular Cell, vol. 35, no. 5, pp. 610-625, 2009.

[157] L. Ma, J. Young, H. Prabhala et al., "MiR-9, a MYC/MYCNactivated microRNA, regulates E-cadherin and cancer metastasis," Nature Cell Biology, vol. 12, no. 3, pp. 247-256, 2010.

[158] P. Gao, I. Tchernyshyov, T.-C. Chang et al., "C-Myc suppression of miR-23a/b enhances mitochondrial glutaminase expression and glutamine metabolism," Nature, vol. 458, no. 7239, pp. 762$765,2009$.

[159] M. Sachdeva, S. Zhu, F. Wu et al., "p53 represses c-Myc through induction of the tumor suppressor miR-145," Proceedings of the National Academy of Sciences of the United States of America, vol. 106, no. 9, pp. 3207-3212, 2009.

[160] A. Arnold and A. Papanikolaou, "Cyclin D1 in breast cancer pathogenesis," Journal of Clinical Oncology, vol. 23, no. 18, pp. 4215-4224, 2005.

[161] D. J. Liao and R. B. Dickson, "c-Myc in breast cancer," EndocrineRelated Cancer, vol. 7, no. 3, pp. 143-164, 2000.

[162] J. Chen, H. E. Feilotter, G. C. Paré et al., "MicroRNA-193b represses cell proliferation and regulates cyclin D1 in melanoma," American Journal of Pathology, vol. 176, no. 5, pp. 2520$2529,2010$. 
[163] W. Xia, J. Li, L. Chen et al., "MicroRNA-200b regulates cyclin D1 expression and promotes S-phase entry by targeting RND3 in HeLa cells," Molecular and Cellular Biochemistry, vol. 344, no. 1-2, pp. 261-266, 2010.

[164] P. Bhat-Nakshatri, G. Wang, N. R. Collins et al., "Estradiolregulated microRNAs control estradiol response in breast cancer cells," Nucleic Acids Research, vol. 37, no. 14, pp. 4850-4861, 2009.

[165] Q. Jiang, M.-G. Feng, and Y.-Y. Mo, "Systematic validation of predicted microRNAs for cyclin D1," BMC Cancer, vol. 9, article 194, 2009.

[166] Y. Onodera, Y. Miki, T. Suzuki et al., "Runx2 in human breast carcinoma: its potential roles in cancer progression," Cancer Science, vol. 101, no. 12, pp. 2670-2675, 2010.

[167] D. T. Leong, J. Lim, X. Goh et al., "Cancer-related ectopic expression of the bone-related transcription factor RUNX2 in non-osseous metastatic tumor cells is linked to cell proliferation and motility," Breast Cancer Research, vol. 12, no. 5, article R89, 2010.

[168] C. K. Inman and P. Shore, "The osteoblast transcription factor Runx2 is expressed in mammary epithelial cells and mediates osteopontin expression," Journal of Biological Chemistry, vol. 278, no. 49, pp. 48684-48689, 2003.

[169] J. Pratap, K. M. Imbalzano, J. M. Underwood et al., "Ectopic Runx2 expression in mammary epithelial cells disrupts formation of normal acini structure: implications for breast cancer progression," Cancer Research, vol. 69, no. 17, pp. 6807-6814, 2009.

[170] K. Das, D. T. Leong, A. Gupta et al., "Positive association between nuclear Runx2 and oestrogen-progesterone receptor gene expression characterises a biological subtype of breast cancer," European Journal of Cancer, vol. 45, no. 13, pp. 22392248, 2009.

[171] A. Javed, G. L. Barnes, J. Pratap et al., "Impaired intranuclear trafficking of Runx2 (AML3/CBFA1) transcription factors in breast cancer cells inhibits osteolysis in vivo," Proceedings of the National Academy of Sciences of the United States of America, vol. 102, no. 5, pp. 1454-1459, 2005.

[172] M. Tomé, P. López-Romero, C. Albo et al., "MiR-335 orchestrates cell proliferation, migration and differentiation in human mesenchymal stem cells," Cell Death and Differentiation, vol. 18, no. 6, pp. 985-995, 2011.

[173] M. Q. Hassan, J. A. R. Gordon, M. M. Beloti et al., "A network connecting Runx2, SATB2, and the miR-23a 27a 24-2 cluster regulates the osteoblast differentiation program," Proceedings of the National Academy of Sciences of the United States of America, vol. 107, no. 46, pp. 19879-19884, 2010.

[174] J. Huang, L. Zhao, L. Xing, and D. Chen, "MicroRNA-204 regulates Runx2 protein expression and mesenchymal progenitor cell differentiation," Stem Cells, vol. 28, no. 2, pp. 357-364, 2010.

[175] Z. Li, M. Q. Hassan, S. Volinia et al., "A microRNA signature for a BMP2-induced osteoblast lineage commitment program," Proceedings of the National Academy of Sciences of the United States of America, vol. 105, no. 37, pp. 13906-13911, 2008.

[176] R. Spizzo, M. S. Nicoloso, L. Lupini et al., "MiR-145 participates with TP53 in a death-promoting regulatory loop and targets estrogen receptor- $\alpha$ in human breast cancer cells," Cell Death and Differentiation, vol. 17, no. 2, pp. 246-254, 2010.

[177] D. Barh, S. Parida, B. P. Parida, and G. Viswanathan, "Let-7, miR-125, miR-205, and miR-296 are prospective therapeutic agents in breast cancer molecular medicine," Gene Therapy and Molecular Biology, vol. 12, no. 2, pp. 189-206, 2008.
[178] J. Pratap, M. Galindo, S. K. Zaidi et al., "Cell growth regulatory role of Runx2 during proliferative expansion of preosteoblasts," Cancer Research, vol. 63, no. 17, pp. 5357-5362, 2003.

[179] J. Pratap, J. B. Lian, A. Javed et al., "Regulatory roles of Runx2 in metastatic tumor and cancer cell interactions with bone," Cancer and Metastasis Reviews, vol. 25, no. 4, pp. 589-600, 2006.

[180] K. Blyth, F. Vaillant, L. Hanlon et al., "Runx2 and MYC collaborate in lymphoma development by suppressing apoptotic and growth arrest pathways in vivo," Cancer Research, vol. 66, no. 4, pp. 2195-2201, 2006.

[181] M. Stewart, A. Terry, M. Hu et al., "Proviral insertions induce the expression of bone-specific isoforms of PEBP $2 \alpha \mathrm{A}$ (CBFA1): evidence for a new myc collaborating oncogene," Proceedings of the National Academy of Sciences of the United States of America, vol. 94, no. 16, pp. 8646-8651, 1997.

[182] J. Pratap, J. J. Wixted, T. Gaur et al., "Runx2 transcriptional activation of Indian Hedgehog and a downstream bone metastatic pathway in breast cancer cells," Cancer Research, vol. 68, no. 19, pp. 7795-7802, 2008.

[183] R. Hu, W. Liu, H. Li et al., "A Runx2/miR-3960/miR-2861 regulatory feedback loop during mouse osteoblast differentiation," Journal of Biological Chemistry, vol. 286, no. 14, pp. 12328-12339, 2011. 


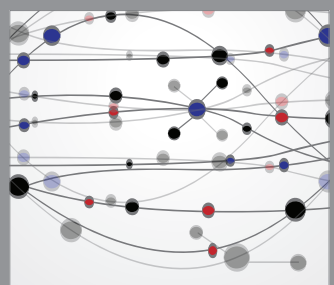

The Scientific World Journal
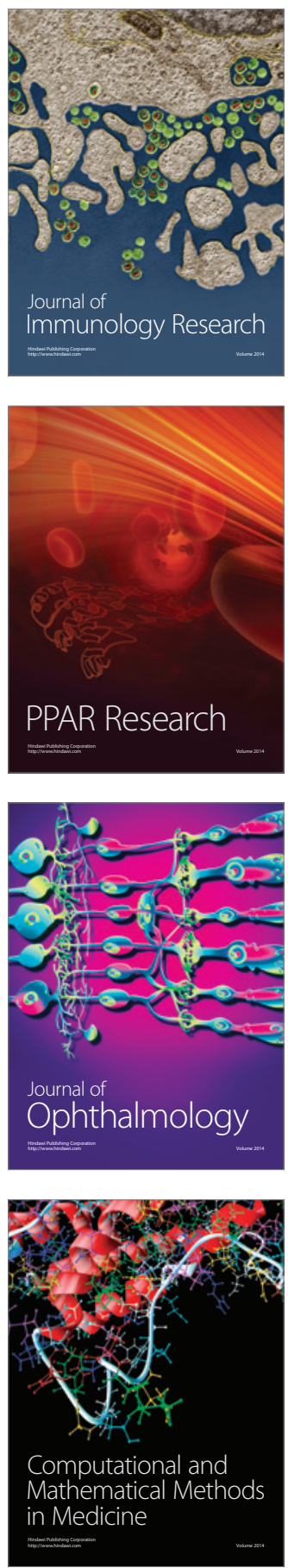

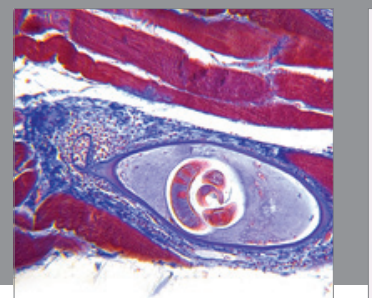

Gastroenterology

Research and Practice
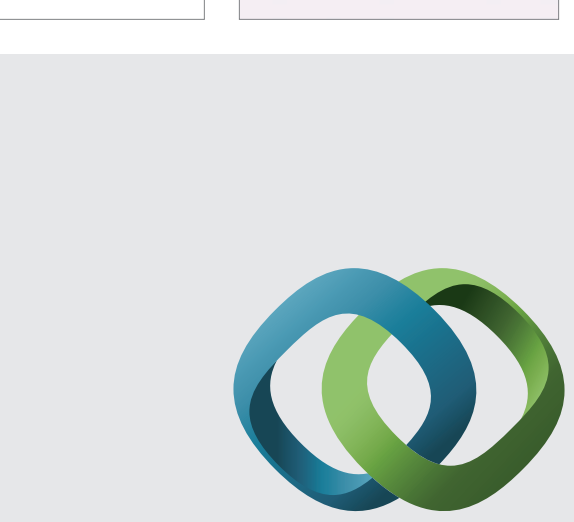

\section{Hindawi}

Submit your manuscripts at

http://www.hindawi.com
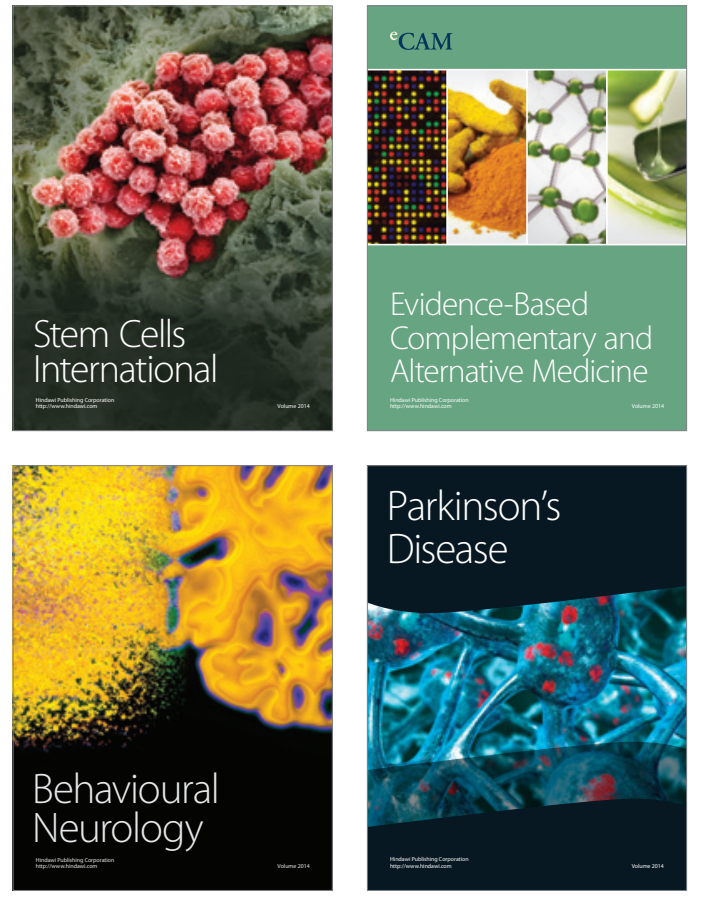
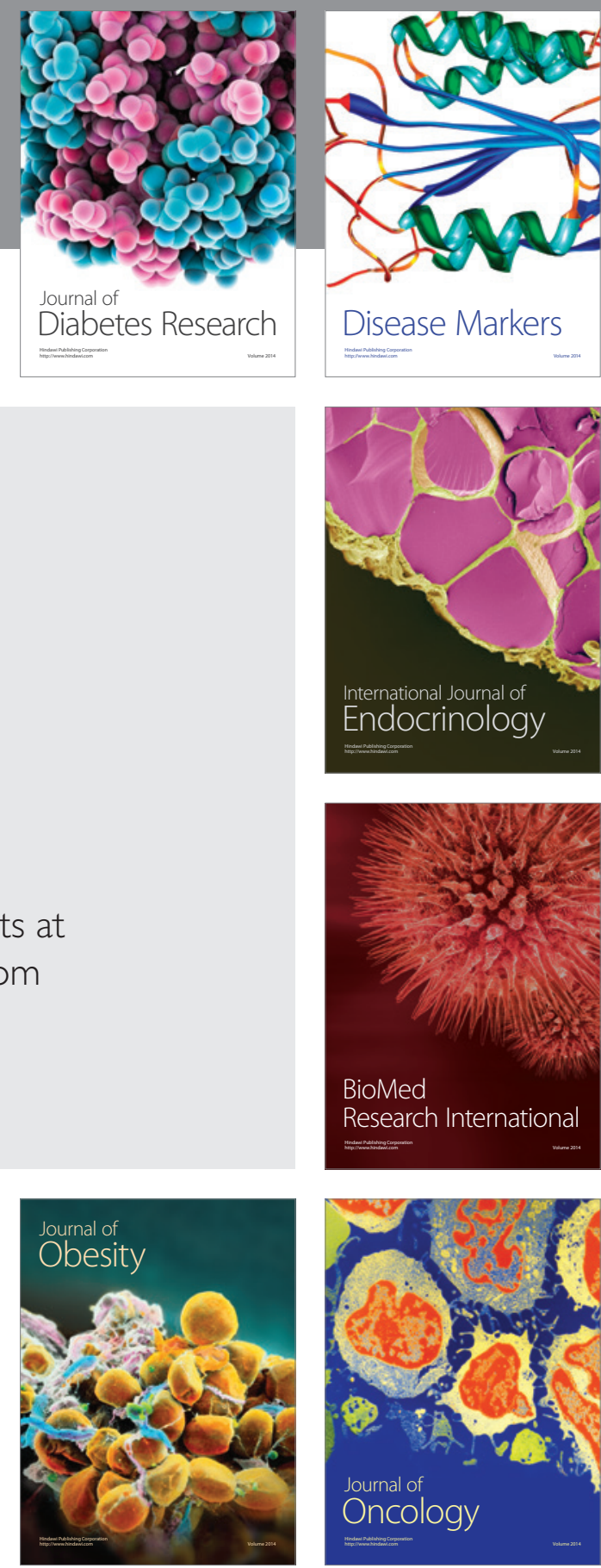

Disease Markers
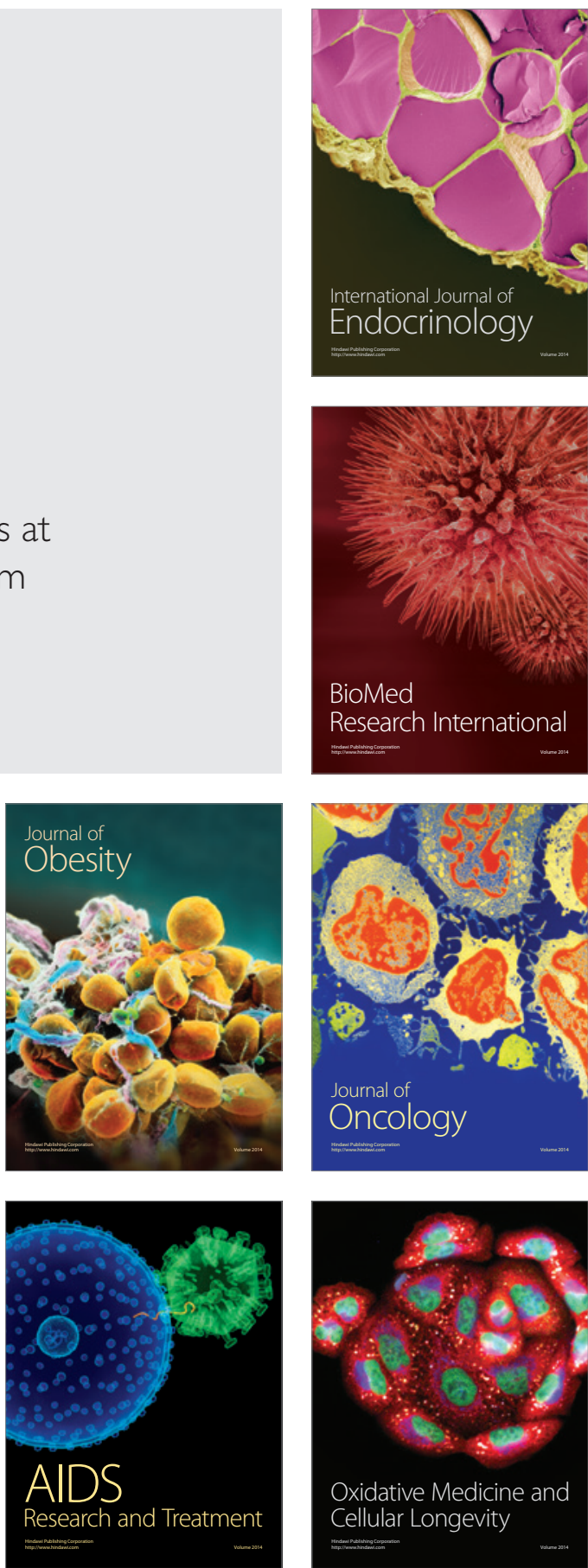